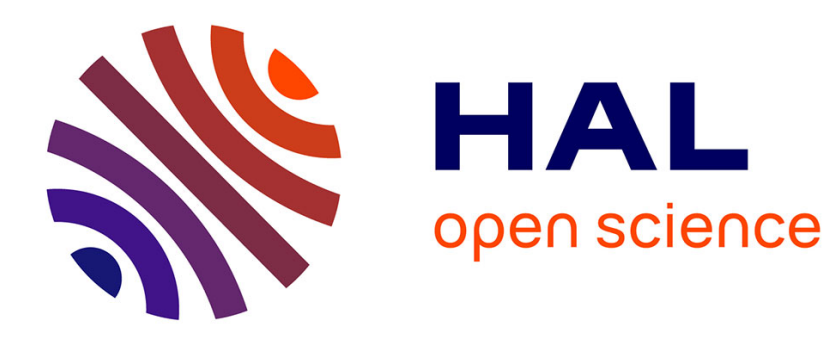

\title{
Information processing in the axon
}

Dominique Debanne

\section{To cite this version:}

Dominique Debanne. Information processing in the axon. Nature Reviews Neuroscience, 2004, 5 (4), pp.304-316. 10.1038/nrn1397 . hal-01766862

\section{HAL Id: hal-01766862 \\ https://hal-amu.archives-ouvertes.fr/hal-01766862}

Submitted on 27 Aug 2018

HAL is a multi-disciplinary open access archive for the deposit and dissemination of scientific research documents, whether they are published or not. The documents may come from teaching and research institutions in France or abroad, or from public or private research centers.
L'archive ouverte pluridisciplinaire HAL, est destinée au dépôt et à la diffusion de documents scientifiques de niveau recherche, publiés ou non, émanant des établissements d'enseignement et de recherche français ou étrangers, des laboratoires publics ou privés. 


\section{INFORM ATION PROCESSING IN THEAXON}

\section{DominiqueDebanne}

Axons link distant brain regions and are generally regarded as reliable transmission cables in which stable propagation occurs once an action potential has been generated. However, recent experimental and theoretical data indicate that the functional capabilities of axons are much more diverse than traditionally thought. Beyond axonal propagation, intrinsic voltage-gated conductances together with the intrinsic geometrical properties of the axon determine complex phenomena such as branch-point failures and reflected propagation. This review considers recent evidence for the role of these forms of axonal computation in the short-term dynamics of neural communication.

GAPJUNCTIONS

M orphological equivalent of electrical synapses. They are composed of two pairs of six connexins that form two apposed hemichannels constituting a pore between two neurons.

TETRODOTOXIN

A neurotoxin derived from the Fugu, or puffer fish, which specifically and reversibly blocks voltage-gated sodium channels.

EquipeINSERM AVENIR, Plasticitédel'excitabilité neuronale, Neurobiologie desCanaux Ioniques INSERM U641, Institut Fédératif de Recherchejean Roche, Universitédela Méditerranée, Boulevard Pierre Dramard, 13916 Marseille, France. e-mail: debanned@ jean-roche.univ-mrs.fr
Sincethe pioneering work of Santiago Ramón y Cajal, theaxon has been defined as a long neuronal process that insures the conduction of information from the cell body to thenerveterminal ${ }^{1}$. Generally, axonsare highly ramified and contact several hundred target neurons locally or distally. H owever, the function of theaxon is not limited to conduction of the action potential from its site of initiation near the cell body to theterminal. Recent experimental findings have shed new light on the functional and computational capabilities of single axons, indicating that several different, complex operations arespecifically achieved along the axon. Decreased conduction or backward propagation (reflection) might occur at specific axonal branch points under a defined regime of activity. Axonal geometry and the biophysical properties of axonal voltage gated channels determine the timing of propagation of the output message in different axonal branches. In addition, axons link central neurons through GAP JUNCTIONs that allow ultra-fast network synchrony. Local shaping of the axonal action potential might subsequently determinesynaptic efficacy during repetitive stimulation. These operations have been primarily described from observation of in vitro preparations of brain tissue, and evidence for these processes is scarce in themammalian brain in vivo. In this article, I review thedifferent ways in which theproperties of axons can modify thetransmission of electrical signals. I begin with a brief discussion of the basic characteristics of propagation and how intrinsic channels that are present in theaxon shapetheaction potential. I then consider two structural specializations that affect theway in which signals are propagated down the axon (branch pointsand varicosities) , and review three ways in which thesefeatures can affect propagation - by introducing conduction delays, by causing propagation failuresand by causing theaction potential to bereflected.

\section{$\mathrm{K}^{+}$and $\mathrm{Na}^{+}$channels in the axon}

Propagation of an action potential isinsured by local activation of sodium channels. Evidence for this was first provided by Hodgkin and Huxley in the giant squid axon (reviewed in REF. 2). Reduction of the sodium gradient or selective blockade of sodium channels by TETROD OTOXIN (TTX) prevents conduction. So, sodium channel activation can be considered as the motor for action potential conduction along axons. The molecular nature of sodium channels in myelinated and unmyelinated axons has been reviewed elsewhere?.

If thesodium channel isthemotor for active propagation along axons, potassium channels providefunctional opposition to action potential conduction. For example, demyelination of sciatic nerves exposes voltage-gated potassium channels that normally liebehind the myelin to theextracellular space 4 . The resulting outward current is responsiblefor propagation failures along the nerve because the voltage threshold of the action potential 


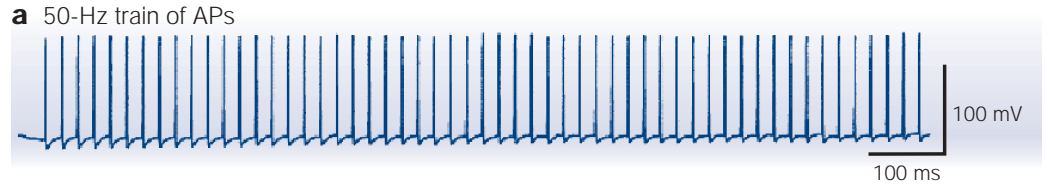

b

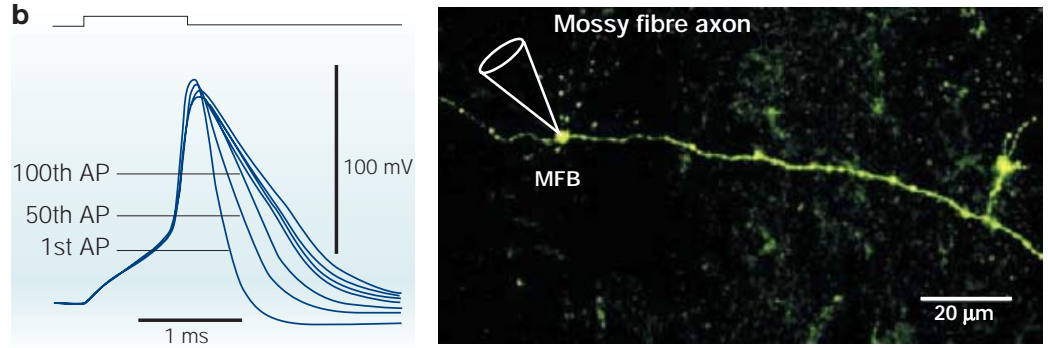

C
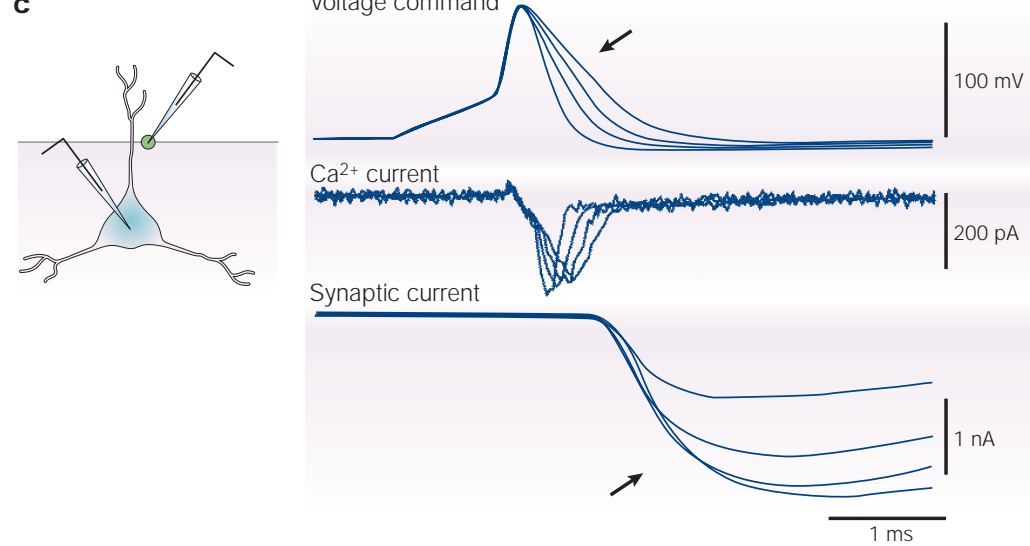

Figure 1 | Shaping of the action potential in the axon. a |A mossy fibre bouton (MFB) is recorded in the whole-cell configuration and activated at a frequency of $50 \mathrm{~Hz}$. $\mathbf{b}$ |During repetitive stimulation of the axon, the action potential (AP) becomes wider. Every fiftieth AP is compared with the first AP in the train. c |AP broadening potentiates transmitter release. The mossy fibre terminal (green) and the corresponding CA3 cell (blue) were recorded simultaneously. AP waveforms were imposed at the presynaptic terminal. The increased duration of the waveform incremented the presynaptic calcium current and potentiated the amplitude of the synaptic current. Adapted, with permission, from REF. 31 @ (2000) Cell Press.

is locally raised as the result of an additional increase in membrane conductance. Theblock of conduction can be overcome by pharmacological blockade of voltage gated potassium channels ${ }^{4,5}$. Several subtypes of voltage-gated potassium channels have been identified in myelinated and unmyelinated axons. $\mathrm{K}_{v} 1.1, \mathrm{~K}_{v} 1.2, \mathrm{~K}_{v} 1.4, \mathrm{~K}_{v} 3.1$ and $\mathrm{K} 3.4$ have been identified in mammalian axons ${ }^{6-14}$. In addition, large-conductancecalcium-dependent potassium channels (BK, also called Maxi-K or Slol channels) are present in axons and presynaptic terminals ${ }^{15-19}$. Finally, largeconductancesodium-dependent potassium channels ( $\mathrm{K}_{\mathrm{Na}^{\prime}}$ also called Slack channels or Slo2.2) are found in myelinated axons ${ }^{20,21}$. All of these potassium channels usually accel erate the repolarization of the action potential, but they might also prevent repetitive dischargeand reducethewidth of theaction potential.

M ore recently, other types of voltage-gated channels have been discovered in axons. Thehyperpolarizationactivated non-selective cationic current $\left(I_{h}\right)$ is present in spinal root axons ${ }^{22}$, leech neurons ${ }^{23}$, optic nerve fibres $^{24}$, crayfish axons ${ }^{25,26}$, cerebellar basket cell axons ${ }^{27}$ and at the calyx of $\mathrm{Held}^{28} . \mathrm{I}_{\mathrm{h}}$ is an inward cationic current that is slowly activated by hyperpolarization. The molecular basis of $I_{h}$ was revealed by the recent cloning of the hyperpolarization-activated, cyclic-nucleotide-gated, cationic non-selective channel subunits 1-4 (HCN 1-4). In the axon, HCN 1-4 have an important regulatory role and dampen shifts in membrane potentials. Another cationic channel that is activated by $\mathrm{G}$ protein-dependent receptors - the heteromeric TRPC1/TRPC5 channel - has been reported in axons of cultured hippocampal neurons ${ }^{29}$. These channels generate an inward current and might regulate the growth of axons in developing neurons ${ }^{30}$, but their precise function in mature axons remains largelyunknown.

\section{Functional computation in the axon}

The shape of the presynaptic action potential is of fundamental importancein determining the strength of synapses by modulating transmitter release. The waveform of the depolarization dictates the cal cium signal that is availableto trigger vesiclefusion by controlling the opening of voltage-gated calcium channels and the driving force for calcium influx. Two types of modification of the presynaptic action potential have been reported experimentally - modification of width and/or modification of amplitude.

Activity-dependent broadening of presynaptic action potentials. The duration of the presynaptic spike is not fixed and activity-dependent short-term broadening of the spikehas been observed in en passant mossy fibre boutons ${ }^{31}$. Themossy fibre-CA3 pyramidal cell synapse exhibits fast and synchronized transmitter release from several active zones and dynamic changes in synaptic strength over a morethan tenfold range. The exceptionally large synaptic facilitation is in clear contrast to the weak facilitation ( 150\%) that is observed at most central synapses. Granulecell axons have several voltage-gated potassium channels including $\mathrm{K}_{v} 1.1$ (REF. 32), $\mathrm{K}_{\mathrm{v}} 1.2$ (REF.7) and two A-type potassium channels, $K_{v} 1.4$ (REFS6,10,11) and $K_{v} 3.4$ (REF. 10). Geiger and Jonas have shown that the action potential at the mossy fibre terminal is half as wide as that at the soma. During repetitivestimulation, theaction potential gets broader in theaxon terminal but not in the soma ${ }^{31}$ (FIG. 1). Using simultaneous recordings from the granulecell terminal and the corresponding postsynaptic apical dendrite of a CA 3 neuron, Geiger and Jonas showed that action potential broadening enhanced presynaptic calcium influx and doubled the amplitude of the excitatory postsynaptic current (FIG.1). This broadening results from the inactivation of A-type potassium channelsthat are located in the membrane of theterminal. Consequently, the pronounced short-term facilitation probably results from the conjugated action of spike widening and the classical accumulation of residual calcium in the presynaptic terminal. Because ultrastructural analysis revealsA-typechannel immunoreactivity in the terminal and in the axonal membrane ${ }^{11}$, activity-dependent spike broadening might al so occur in theaxon. 


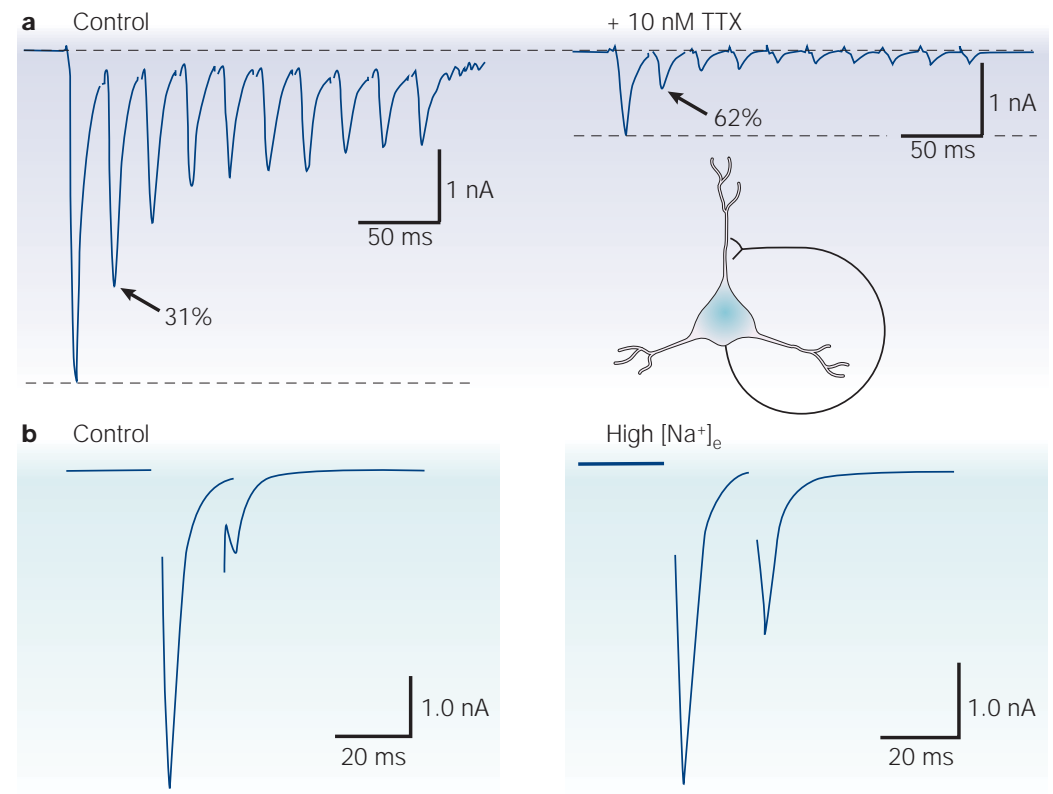

c

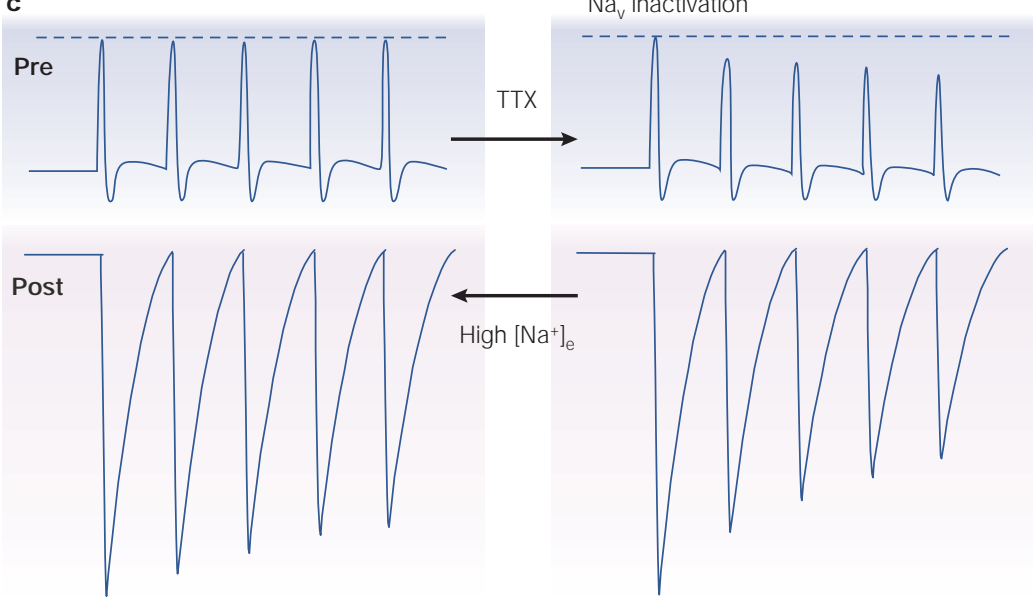

Figure 2 | The role of sodium channel inactivation in short-term synaptic depression. a Repetitive stimulation of an autaptic contact produces short-term depression. The application of a low concentration of the channel blocker tetrodotoxin (TTX) reduces synaptic transmission and enhances short-term depression. Adapted, with permission, from REF. 36 @ (2000) Society for Neuroscience. $\mathbf{b}$ | Rescue of paired-pulse transmission by elevation of the extracellular sodium concentration $\left(\left[\mathrm{Na}^{+} \mathrm{l}_{\mathrm{e}}\right)\right.$. The large paired-pulse depression that is observed at an autaptic contact of a cultured hippocampal cell is dramatically reduced when $\left[\mathrm{Na}^{+}\right]$is increased by $40 \mathrm{mM}$. Adapted, with permission, from REF. 38 ๑ (2002) The American Physiological Society. c | Hypothetical regulation of short-term depression by the modulation of activity-dependent attenuation of presynaptic spike amplitude. Sodium channel inactivation (TTX, right column) attenuates the spike train and enhances depression. Reduced inactivation (high [ $\left.\mathrm{Na}^{+}\right]_{e}$, left column) opposes both presynaptic spike attenuation and short-term depression.

PAIRED-PULSE FACILITATION If two stimuli are delivered in close succession to an axon, the postsynaptic response to the second stimulus is often larger than to thefirst one. This phenomenon is referred to as paired-pulse facilitation, and is thought to depend on the accumulation of $\mathrm{Ca}^{2+}$ that ensues after successivestimuli.
(FIG. 2a; S. Boudkkazi, E. Carlier \& D.D., unpublished observations). In addition, depolarization of the presynaptic terminal by raising the external potassium concentration increases paired-pulse depression at autaptic contacts of cultured hippocampal cell $\mathrm{s}^{38}$ and decreases PAIRED-PULSE FACILITATION at Schaffer collateral-CA1 synapses ${ }^{38}$. In this case, depolarization of the presynaptic axons probably enhances presynaptic spikeattenuation. Importantly, inactivation of sodium channels by high external concentrations of potassium increases the proportion of conduction failures during repetitive stimulation of Schaffer collateral axons $\mathrm{s}^{39}$. Alternatively, paired-pulsedepression can bereduced by increasing the external concentration of sodium, perhaps acting to suppress presynaptic spike attenuation ${ }^{38}$ (FIG. 2b). These data indicate that slow recovery of sodium channels from inactivation might havean important rolein shaping the short-term dynamics of synaptic transmission.

Interestingly, the manipulations of the sodium current that are mentioned above have no or little effect on GABA ( $\gamma$-aminobutyric acid)-containing axons $^{37-39}$. RILUzOLE, TTX or external potassium do not affect GABA-mediated synaptic transmission or short-term GABA-mediated plasticity. This difference between glutamatergic and GABA-containing axons might result from several factors. Sodium currents in interneurons are less sensitiveto inactivation, and slow recovery from inactivation has been observed for pyramidal cells but not for inhibitory interneurons ${ }^{40}$. M oreover, the density of sodium current is greater in interneurons than in pyramidal neurons ${ }^{41}$. So, axons of GABA-containinginterneurons could be better cables for propagation than those of pyramidal cell $S^{42,43}$. This unusual property could be functionally important safe propagation along inhibitory axons could protect the brain from sporadic hyperactivity.

Axonal arborization: branch pointsand varicosities. In addition to affecting conductances, axonal morphology influences information processing in theaxon. Axonal morphology is highly variable. At one extreme, axons of cerebellar granule cells possess a singleT-shaped branch point that gives rise to the parallel fibres (FIG.3a). At the other extreme, many axons typically form an elaborate tree. For instance, theterminal arbor of thalamocortical axonsin layer IV of the cat visual cortex contains 150 to 275 branch points $^{44}$ (FIG. 3b). The complexity of axonal arborization is also extensive in cortical pyramidal neurons $^{45}$ (FIG. 3C). Axons of hippocampal CA 3 pyramidal cells have at least 100 to 200 branch points in a total axonal length of 150 to $300 \mathrm{~mm}$, and a single cell might contact 30,000 to 60,000 neurons $s^{46-48}$. But the champions of axonal complexity might beGABA-containing interneurons of different brain regions (FIG. 3d). Hippocampal and cortical inhibitory interneurons emit an axon with denseand highly branched arborization ${ }^{49}$. Oneobvious function of axonal divergenceis to allow synchronous transmission to a wide population of target neurons within a given brain area. But branching axons might also link brain territories that areinvolved in complementary functional tasks, such as perception and action ${ }^{50}$. 

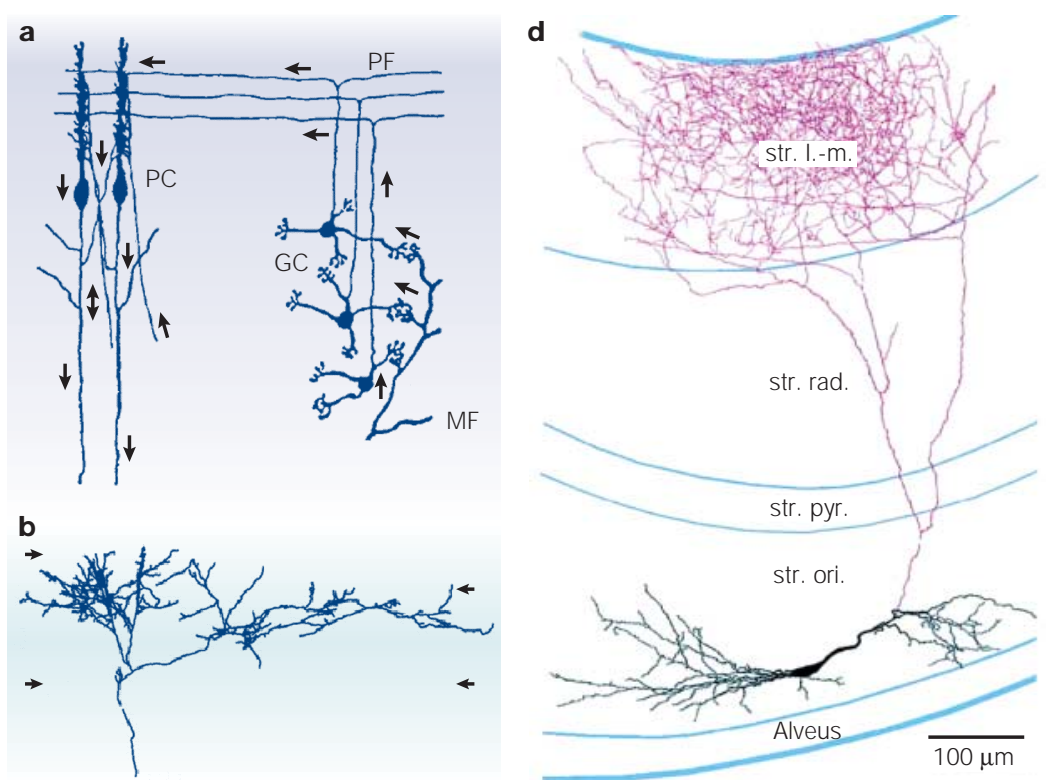

C
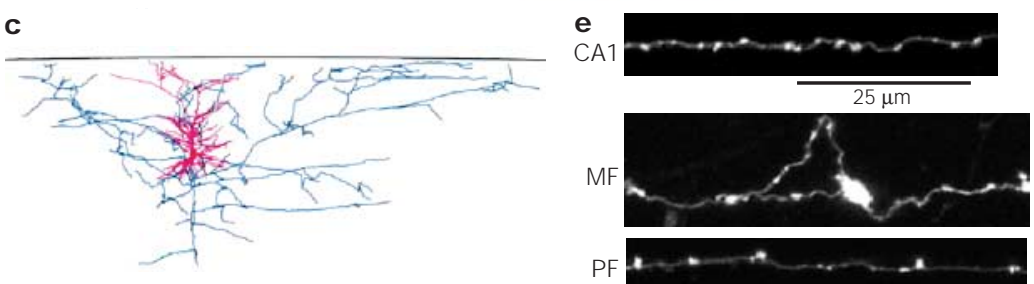

Figure 3 | Branch points and varicosities. a |Drawing of the cerebellar afferent circuit. Mossy fibre (MF) activity excites granule cells (GC) whose axons project towards the surface of the cortex. The GC axon bifurcates into two branches, which form the parallel fibres (PFs). Adapted from REF. 1.

b | Reconstruction of the terminal bouquet of a thalamocortical axon in area 17 of the cat. Horizontal arrowheads indicate the limits of layer IV. Adapted, with permission, from REF. 44 @ (1998) Society for Neuroscience. c |Dendritic (red) and axonal (blue) arborizations of a layer II pyramidal neuron in the barrel cortex. Adapted, with permission, from REF. 45 (c) (2003) Society for Neuroscience. d |Camera lucida reconstruction of a hippocampal GABA ( $\gamma$-aminobutyric acid)-containing interneuron. The dendritic arbor is represented in black and the dense axonal arborization in red. Adapted, with permission, from REF. 41 (c) (2000) American Association for the Advancement of Science. Str. I.-m.; stratum lacunosum-moleculare; str. ori.; stratum oriens; str. pyr.; stratum pyramidale; str. rad.; stratum radiatum. e | Varicosities on stratum oriens axons in the CA1 area (upper), on MF axons in area CA3 (middle) and on cerebellar PFs (bottom). Adapted, with permission, from REF. 53 (C) (2002) The National Academy of Sciences.

RILUZOLE

2-amino-6-trifluoromethoxybenzothiazole). A voltage dependent sodium channel blocker that is used as an anticonvulsant.
The second morphological feature of axons is the presence of many varicosities (synaptic boutons) that are commonly distributed in an en passant, 'beads-on-astring' manner along thin axon branches (FIG. 3e). A single axon can contain several thousands of boutons ${ }^{48,49,51}$. Bouton size varies between $\sim 1 \mu \mathrm{m}$ for thin unmyelinated axons $\mathrm{s}^{52,53}$, to between 3 and $5 \mu \mathrm{m}$ for largemossy fibre terminals of the hippocampus ${ }^{53,54}$. Their density varies among axons and the spacing between varicosities ranges from $\sim 4 \mu \mathrm{m}$ to $\sim 6 \mu \mathrm{m}$ in unmyelinated axons ${ }^{53,55}$.

Length and diameter also contribute to thevariability of axons. Someaxons extend locally (about $1 \mathrm{~mm}$ for inhibitory interneurons) whereas others can beas long as 1 metre or more. The diameter of axons also varies considerably. Thelargest axon (the squid giant axon) is close to $1 \mathrm{~mm}$ in diameter ${ }^{56}$ whereas the diameter of unmyelinated cortical axons varies between 0.08 and $0.4 \mu \mathrm{m}$ (REFS52,57).

\section{Axonal propagation and spike timing}

The timing of action potentials is thought to determine the coding of neuronal information in the brain. Axonal conduction introduces a delay into the propagation of neuronal output, and axonal arborization might transform a temporal pattern of activity in the main axon into spatial patterns in the terminal $s^{58}$. Axonal delay initially depends on the velocity of the action potential in axons (generally between $0.1 \mathrm{~m} \mathrm{~s}^{-1}$ in unmyelinated axons and $100 \mathrm{~m} \mathrm{~s}^{-1}$ in large myelinated axons), which is a direct function of the diameter of the axon and the presence of a myel in sheath. Axonal delays might have crucial functional consequences for the integration of sensory information. In the first relay of the auditory system of the barn owl, differences in the delay of axonal conduction from each ear (which in this case is a function of differences in axonal length) produce sharp temporal tuning of the binaural information that is essential for acute sound localization ${ }^{59-61}$. In addition to this initial delay, local changes in the geometry of theaxon produce an extra delay.

The presence of axonal irregularities such as varicosities and branch points reduces the conduction velocity (FIG. 4a). This reduction in conduction velocity occurs as a result of a high geometrical ratio (GR) (BOX 1). The degree of temporal dispersion has been simulated for an axon from the somatosensory cortex of the cat ${ }^{62}$. The delay introduced by high $\mathrm{GR}$ branch points could account for a delay of between 0.5 and $1 \mathrm{~ms}$ (REF. 62). But this extra del ay seems rather small compared with the delay that is imposed by conduction in axon branches with variable lengths (in the range of 2-4 ms).

A third source of delays in conduction is repetitive stimulation or activation of specific ion channels. The magnitude of this type of delay is usually variable, and it has been measured in a few cases. In lobster axons, the conduction velocity of the axon was decreased by $\sim 30 \%$ following repetitivestimulation ${ }^{33}$. In dorsal root ganglion neurons, the latency of conducted spikes was enhanced by about 1 msfollowing antidromic pairedpulsestimulation of the axon ${ }^{63}$. Computational studies indicate that this delay might also result from a local distortion of the shape of the action potential. Extra activity-dependent delays might have important consequences for synaptic transmission. For instance, the synaptic delay was extended by 1-2 ms during repetitive stimulation of crayfish motor neurons ${ }^{64}$. Monosynaptic connections to motor neurons show an increase in synaptic latency concomitant with the synaptic depression that is induced by repetitive stimulation at $5-10 \mathrm{~Hz}$ and that induced near-propagation failures ${ }^{65}$. Similarly, a longer synaptic delay has been measured between connected hippocampal cells when conduction nearly fails owing to reactivation of A-type potassium channels ${ }^{66}$ (FIG. 4b). So, axonal conduction might introduce somenoise into the temporal pattern of action potentials that is produced at the initial segment. At the scale of a nerve, delays in individual axons introduce a temporal dispersion of conduction, indicating a model of stuttering propagation ${ }^{67}$. 
a
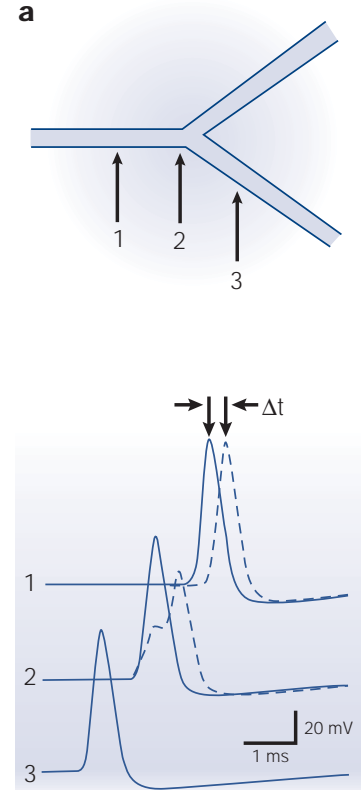

b
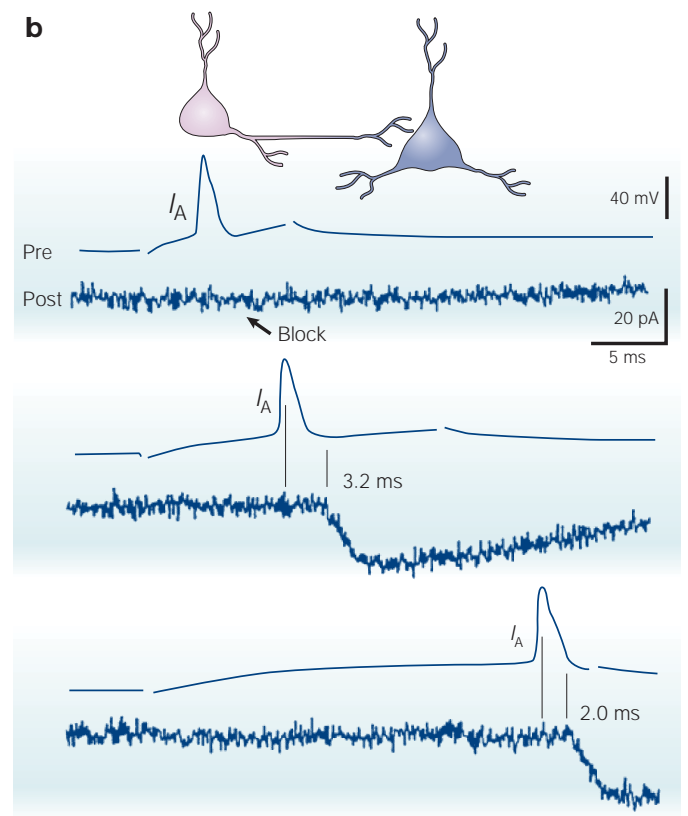

Figure 4 | Axonal propagation and spike timing. a | Comparison of the delay of propagation introduced by a branch point with a geometrical ratio (GR) $>1$ (dashed traces) versus a branch point with perfect impedance matching ( $G R=1$, continuous traces). Upper, schematic drawing of a branched axon with three points of recording. At the branch point with $G R=8$, the shape of the action potential is distorted and the propagation displays a small latency $(\Delta t)$. Adapted, with permission, from REF. $62 \odot$ (1991) The Biophysical Society. b | Propagation failures in hippocampal cell axons are associated with conduction delays. The presynaptic neuron (Pre) was slightly hyperpolarized with constant current to remove inactivation of the A-current. A presynaptic action potential induced with a short delay after onset of the depolarizing pulse did not elicit excitatory postsynaptic current in the postsynaptic cell (Post) because of the large activation of $\mathrm{I}_{A}$. Increasing the delay permitted action potential propagation because $I_{A}$ was reduced during the action potential. For complete inactivation of $\mathrm{I}_{\mathrm{A}}$ (lower pair of traces), latency decreased. Adapted, with permission, from REF. $66 \odot$ (1997) Macmillan Magazines Ltd.

\section{Propagation failures}

One of the more unusual operations of axons is selective conduction failure. When the action potential failsto propagatealong the axon, no signal can reach the output of the cell. Conduction failure filters communication with postsynaptic neurons, and has been observed experimentally in various axons including vertebrate spinal axon $s^{68,69}$, spiny lobster or crayfish motor neurons $\mathrm{s}^{33,64,70,71}$, leech mechanosensory neurons $\mathrm{s}^{72-76}$, thalamocortical axons $\mathrm{s}^{77}$, rabbit nodoseganglion neurons ${ }^{78}$, rat dorsal root ganglion neuron $s^{63,79}$, neurohypophysial axons ${ }^{17,80}$ and hippocampal pyramidal cell $s^{39,66,81}$. Several factors determinewhether propagation along axons fails or succeeds.

Geometrical factors: branch points and swellings. Although the possibility that propagation might fail at branch points was previously discussed by Krnjevic and $\mathrm{M}$ iledi ${ }^{69}$, the first clear indication that propagation is perturbed by axonal branch points came from the early studies on spiny lobster, crayfish and leech

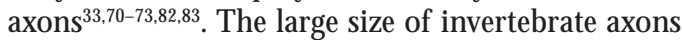
allowed multi-electrode recordings upstream and downstream of the branch point to be performed. For example, in lobster axons, conduction across the branch point was found to fail at frequencies above $30 \mathrm{~Hz}$ (REF. 33) (FIG. 5a). The block of conduction occurred

specifically at thebranch point because the parent axon and oneof the daughter branches continued to conduct action potentials. Failures appeared first in thethicker daughter branch, but they werealso observed in the thin branch at a higher stimulus frequency. In the leech, conduction block occurs at central branch points where fine axons from the periphery meet thicker axons ${ }^{73}$. Branch point failures have been observed or are suspected to occur in a number of mammalian neuron $5^{66,77,78}$.

Propagation failures also occur when the action potential enters a zone wherein the diameter changes abruptly. This occurs at en passant boutons ${ }^{84-86}$ but also when impulses propagating along the axon enter the soma ${ }^{63}$. For instance, in the megacerebral cell of the snail, propagation failures have been observed when a spike enters the cell body ${ }^{87}$ (FIG. 5b). Thesefailures occur because the electrical load on the arriving action potential issignificantly higher and the current generated by the parent axon is not sufficient to allow propagation to proceed (see BOX 1).

Frequency-dependent propagation failures. In most cases, failures occur following moderate or high frequency stimulation $(10-50 \mathrm{~Hz})$ of the axon. For instance, a fre quency of $20-30 \mathrm{~Hz}$ is sufficient to produce conduction failures at the neuromuscular terminal arborization ${ }^{69}$ or at the branch point of spiny lobster motor neurons $\mathrm{s}^{33}$. These failures are often observed as partial spikes or spikelets that are electrotonic residues of full action potentials. Thefunctional consequences of conduction failuresmight beimportant in vivo. For example, in the leech, propagation failures producean effect that issimilar to sensory adaptation. Propagation failures area nonsynaptic mechanism that temporarily disconnects the neuron from onedefined set of postsynaptic neurons and specifically routes sensory information in the ganglion ${ }^{72-74,88}$. Propagation failure in theleech is al so a means by which activity al ters electrical synaptic transmission, which, in contrast to chemical synaptic transmission, is resistant to changes that areinduced by activity ${ }^{89}$.

What are the mechanisms of frequency-dependent conduction failure? As mentioned above, the presence of a low safety conduction point such as a branch point, a bottleneck (that is, an axon entering the soma) or an axonal swelling determines the success or failure of conduction ( see also Box 1). H owever, these geometrical constraints are not sufficient to account fully for all conduction failures and additional factors should be considered. The mechanisms of propagation failurecan begrouped in two main categories.

First, propagation can fail during repetitive axon stimulation as a result of a slight depolarization of the membrane(FIG. 6a). At spiny lobster axons, propagation failures were associated with a 10-15\% reduction of the action potential amplitude in the main axon and a membrane depolarization of 1-3 mV (REF. 33). These observations are consistent with potassium efflux into the periaxonal space that is induced by repetitive activation. In most cases, the membrane depolarization that is produced by external accumulation of potassium ions around the axon probably contributes to the inactivation 


\begin{abstract}
Box 1 | Theory of geometrical constraints on axonal propagation
Thefunctional consequences of geometrical irregularities for axonal propagation have been addressed using numerical models (reviewed in REF. 128). Simulations show that at geometrical irregularities, theamplitudeand width of the propagating action potential are usually distorted, and the local conduction velocity can change. For instance, an abrupt increase in axon diameter causes a decrease in both velocity and peak amplitude of the action potential, whereas a sudden reduction of diameter has the opposite local effects on these two parameters ${ }^{62,86,105,135-138}$. In fact, theinterplay between thetotal longitudinal current that is produced by theaction potential and theinput impedance of the axon segments ahead of the action potential determines thefate of the propagating action potential.

The case of the branch point has been studied in detail ${ }^{105,139,140}$.
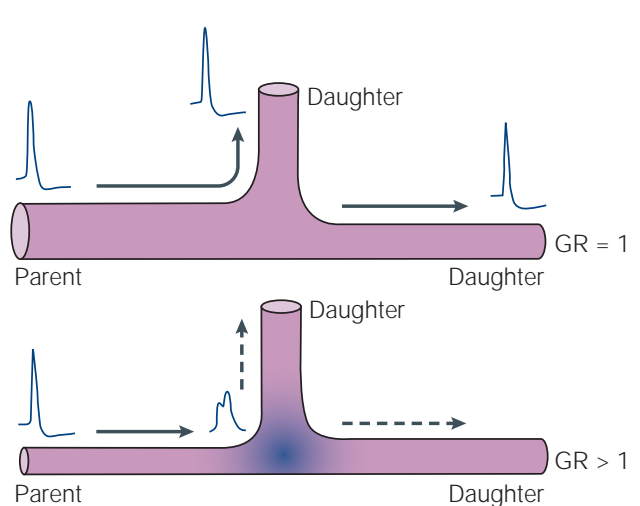

Theso-called $3 / 2$ power law that was developed by Rall describes an ideal relationship between the geometry of mother and daughter branche ${ }^{105,141,142}$. A geometrical parameter (the geometrical ratio, GR) is defined as follows: $G R=\left(d^{3 / 2}{ }_{\text {daughter } 1}+d^{3 / 2}\right.$ daughter 2$) / d^{3 / 2}$ mother , where $d_{\text {daughter } 1}$ and $d_{\text {daughter } 2}$ are the diameters of the daughter branches and $d_{\text {mother }}$ is the diameter of the parent axon. For $\mathrm{GR}=1$, impedances match perfectly and spikes propagate in both branches (upper panel of figure). If $\mathrm{GR}>1$, the combined electrical load of the daughter branches exceeds the load of the main branch (lower panel of thefigure). In other words, the activemembrane of themother branch might not provideenough current to activate both daughter branches. For $1<\mathrm{GR}<10$ - the most common situation - propagation beyond the branch point is delayed. All of these conclusions hold only if the characteristics of the membraneareidentical. Any change in ion channel density might positively or negatively change the probability of sucessful propagation at a given branch point. GR has been experimentally evaluated in a limited number of axon branch points. In lobster axons that innervatethe deep abdominal muscles, GR at the branch point between medial and lateral bundles isclose to theideal value, allowing perfect impedance matching (0.97; REF. 33). In thalamic and cortical axons of thecat, GR at branch points varies between 0.78 and 1.98 (REF. 77). In axons of the crayfish, GR varies between 0.95 and 1.25 (REF. 83). Interestingly, in crayfish and lobster axons, branch points with a high $\mathrm{GR}$ weremoresusceptibleto branch-point failures during repetitivestimulation. In axons of leech pressureneurons, the branch point formed by the thin peripheral axon (mean diameter $2.1 \mu \mathrm{m}$ ) with the principal axon (mean diameter $9.8 \mu \mathrm{m}$ ) has a GR near 20 (REF.75). Branch points also havea very high GR in the giant metacerebral cell from the cerebral ganglia of $\mathrm{H}$ elix. Propagation might fail at low frequency when an activethin axon enters a large diameter axon $^{87}$, indicating that, exceptionally, failures result uniquely from geometrical factors.
\end{abstract}

of sodium channels. In fact, hyperpolarization of the axon membrane or local application of physiological saline with a low concentration of potassium in the vicinity of a block can restore propagation in crayfish axons $^{71}$. Elevation of the extracellular potassium concentration produced conduction block in spiny lobster axons $5^{82}$. H owever, this manipulation did not reproduce the differential block that is induced by repetitivestimulation, as failures occurred simultaneously in both branches ${ }^{82}$. Interestingly, conduction could also be restored by increasing the concentration of intracellular calcium. Failureswerealso induced with a lower threshold when the electrogenic $\mathrm{Na}^{+} / \mathrm{K}^{+}$pump was blocked with ouABain. So, differential conduction block could be explained as follows. During high frequency activation, potassium initially accumulates at the sameratearound theparent axon and the daughter branches. Sodium and calcium accumulate more rapidly in the thin branch than in the thick branch because of the higher surface/volume ratio. The $\mathrm{Na}^{+} / \mathrm{K}^{+}$pump is activated and the concentration of extracellular potassium decreases at a greater rate around the thin branch ${ }^{82}$. Accumulation of extracellular potassium has also been observed in the olfactory nerve $\mathrm{e}^{90}$ and in hippocampal axons ${ }^{91}$, and could betheorigin of unreliableconduction.

Propagation failures that areinduced by repetitive stimulation might also result from hyperpolarization of theaxon (FIG.6b). Hyperpolarization-induced conduction block has been observed in leech ${ }^{72,73,88}$, locust ${ }^{92}$ and mammalian axons $s^{17,78}$. Axonal hyperpolarization opposes spike generation. Activity-dependent hyperpolarization of the axon usually resultsfrom activation of the $\mathrm{Na}^{+} / \mathrm{K}^{+}$ATPase and/or activation of calcium-dependent potassium channels. Unmyelinated axons in the PNS (for example, vagal $\mathrm{C}$-fibres) hyperpolarize in response to repeated action potential $s^{93,94}$ as a result of the intracellular accumulation of sodium ions and the subsequent activation of the electrogenic $\mathrm{Na}^{+} / \mathrm{K}^{+}$pump ${ }^{26,93,94}$. In crayfish axons, this hyperpolarization can have a magnitude of $5-10 \mathrm{mV}$ (REF. 26). Blockade of the $\mathrm{Na}^{+} / \mathrm{K}^{+}$ATPase with ouabain results in axon depolarization, probably as a consequence of post-tetanic changes in the concentration of extracellular potassium. In the leech, hyperpolarizationdependent conduction block occurs at central branch points in all threetypes of mechanosensory neurons in theganglion - touch $(T)$, pressure $(P)$ and nociceptive (N) neurons. In these neurons, hyperpolarization is induced by the $\mathrm{Na}^{+} / \mathrm{K}^{+}$ATPase and by cumulative activation of a calcium-activated potassium conductance. It is interesting to note that the conduction state can be changed by neuromodulatory processes. 5- HT (5-hydroxytryptamine, serotonin) decreases the probability of conduction block of $P$ and $T$ cells, probably by limiting hyperpolarization ${ }^{95}$. 
a

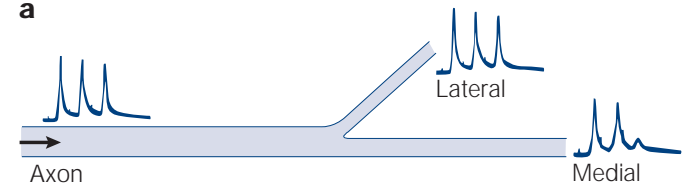

b
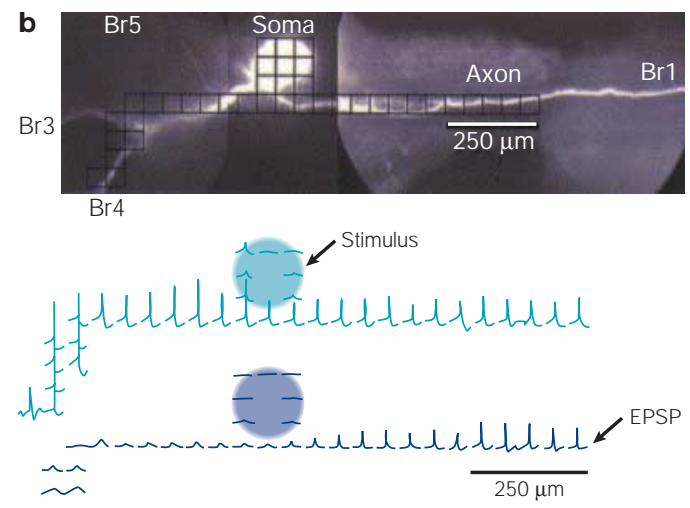

-

Figure 5 | Propagation failures. a | Propagation failure at a branch point in a lobster $a_{x o n^{33}} . \mathbf{b} \mid$ Propagation failure at the junction between an axonal branch and the soma of a snail neuron (metacerebral cell). The propagation in the axonal arborization was analysed by the local fluorescence transients owing to the action potential. The recording region is indicated by an outline of a subset of individual detectors, superimposed over the fluorescence image of the neuron in situ. When the action potential was evoked by direct stimulation of the soma, it propagated actively in all axonal branches (green traces). By contrast, when the action potential was evoked by the synaptic stimulation (EPSP) of the right axonal branch (Br1), the amplitude of the fluorescent transient declined when approaching the cell body, indicating a propagation failure (blue traces). Adapted, with permission, from REF. 87 (C) (2000) The Physiological Society.

Hyperpolarization-dependent failures haveal so been reported in axons of hypothalamic neurons (from paraventricular and supraoptic nuclei) that run into the neurohypophysis. The morphology of their boutons is unusual in that their diameter varies between 5 and $15 \mu \mathrm{m}$ (REF. 85). In singleaxons, propagation failures are observed at stimulation rates that are greater than $12 \mathrm{~Hz}$ and they are concomitant with a hyperpolarization of $4 \mathrm{mV}$ (REF. 17). These failures might account for the non-linear decline in hormone release from the pituitary and theactivity-dependent fatigue of neurosecretion. Theinduced hyperpolarization of theneuron might result from activation of the calcium-dependent BK potassium channel. In fact, action potential failures weremorefrequent when BK channels were indirectly activated by adding the L-type calcium channel agonist Bay K 8644 to the external medium. By contrast, no failures were observed in the presence of the voltagegated calcium channel blocker cadmium, indicating that propagation failuremight result from accumulation of intracellular calcium and activation of $\mathrm{BK}^{17}$. Subsequently, activation of BK channels would decrease axonal excitability and promotefailures of incoming action potentials. Theslow inactivation of the channel is compatible with the critical frequency for propagation failures.
Several recent studies indicate that the hyperpolarization that is produced by repetitive stimulation could be dampened by hyperpolarization-induced cationic current $\left(I_{h}\right)^{26,81}$. This inward current is activated at resting membrane potential and produces a tonic depolarization of the axonal membrane $e^{26}$. So, reduction of this current induces hyperpolarization and perturbs propagation. The pharmacological blockade of $\mathrm{I}_{\mathrm{h}}$ by ZD 7288 or by external caesium can produce more failures in Schaffer collateral axons ${ }^{81}$. The peculiar biophysical properties of $I_{h}$ indicate that it might limit large hyperpolarizations or depolarizations that areproduced by external and internal accumulation of ions. In fact, hyperpolarization of theaxon will activate ${ }_{h}$, which in turn produces an inward current that compensates for the hyperpolarization ${ }^{26}$ (FIG. 6b). Reciprocally, this compensatory mechanism is also valid for depolarization by removing basal activation of $\mathrm{I}_{\mathrm{h}}$.

Frequency-independent propagation failures. Action potential propagation in some axon collaterals of CA 3 pyramidal neurons can be gated by activation of a presynaptic A-type potassium current ${ }^{66}$. Synaptic transmission between monosynaptically coupled pairs of CA3-CA3 or CA3-CA1 pyramidal cells can beblocked if a brief hyperpolarizing current pulse is applied a few milliseconds beforeinduction of the action potential in the presynaptic neuron ( FIG. 7; see also FIG. 4b). This regulation is observed in synaptic connections that have no transmission failures, indicating that the lack of postsynaptic response is a consequence of a conduction failure along the presynaptic axon. Interestingly, failures can also be induced when the presynaptic hyperpolarizing current pulse is replaced by a somatic inhibitory postsynaptic potential66,96. When presynaptic cells are recorded with a microelectrode containing 4-aminopyridine (4-AP), a blocker of $\mathrm{I}_{\mathrm{A}^{-}}$-likeconductances, failures are abolished, which indicates that $\mathrm{I}_{\mathrm{A}}$ gates action potential propagation (see also REF. 97). Because A-channels are partially inactivated at the resting membranepotential, their contribution during an action potential that is elicited from the resting membrane potential is minimal, and the action potential propagates successfully from the cell body to the nerve terminal. By contrast, A-channels recover from inactivation with a transient hyperpolarization and impedesuccessful propagation to theterminal.

Propagation failures have been induced in only $30 \%$ of $\operatorname{cases}^{66}$, showing that propagation is generally reliable in hippocampal axons ${ }^{98-100} . \mathrm{I}_{\mathrm{A}}$-dependent conduction failures occur at some axon collaterals but not at others ${ }^{66}$. Using a theoretical approach, it has been shown that failures occur at branch points when A-type potassium channels are distributed in clusters near the bifurcation ${ }^{96}$. Perhaps because these conditions do not prevail in layer II/III neocortical neurons $\mathrm{s}^{101,102}$ or in dissociated hippocampal neurons ${ }^{99}$, this form of gating has not been reported in these cell types. It would be interesting to explore the actual distribution of potassium channel clusters near branch pointsusing immunofluorescencemethods. 

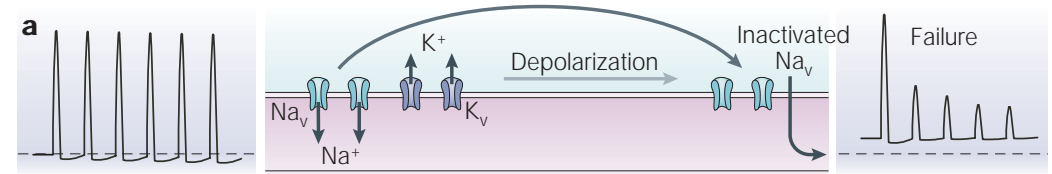

b
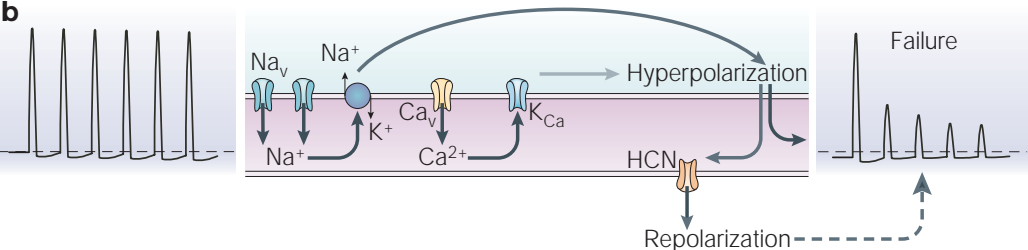

Figure 6 | Mechanisms of propagation failures induced by repetitive stimulation.

a |Activity-dependent depolarization of the axon. Following high frequency stimulation of the axon (burst on the left) activation of voltage-gated potassium channels $\left(\mathrm{K}_{\mathrm{v}}\right)$ produces a large efflux of potassium ions $\left(\mathrm{K}^{+}\right)$that accumulate in the periphery of the axon. The resulting axonal depolarization together with the slow recovery of sodium channels $\left(\mathrm{Na}_{v}\right)$ from inactivation produce conduction failures seen as partial spikes (burst on the right). b |Activity-dependent hyperpolarization of the axon. High frequency stimulation of the axon produces an accumulation of intracellular sodium and intracellular calcium through voltage-gated sodium $\left(\mathrm{Na}_{v}\right)$ and calcium $\left(\mathrm{Ca}_{v}\right)$ channels. Activation of the electrogenic $\mathrm{Na}^{+} / \mathrm{K}^{+}$pump by internal sodium ions and calcium-dependent potassium channels $\left(\mathrm{K}_{\mathrm{Ca}}\right)$ by internal calcium ions hyperpolarizes the axon membrane and produces conduction failures. The hyperpolarization can be partially compensated by activation of the $\mathrm{I}_{H}$ current through hyperpolarization-activated, non-selective cationic ( $\mathrm{HCN}$ ) channels.

Functionally, this form of gating might determinepart of the short-term synaptic facilitation that is observed during repetitive presynaptic stimulation. Apparent paired-pulsefacilitation is observed becausethefirst, but not the second, action potential failsto propagate owing to inactivation of the A-type potassium current ${ }^{103}$. Another voltage gated potassium channel $\left(I_{D}\right)$ has been recently proposed to control synaptic transmission between individual CA3 cells ${ }^{104}$. H owever, additional investigation will be required to determine whether this current also gates action potential propagation.

Reflection of action potential propagation. Branch points areusually regarded as frequency filters, allowing separate branches of an axon to activatetheir synapses at different
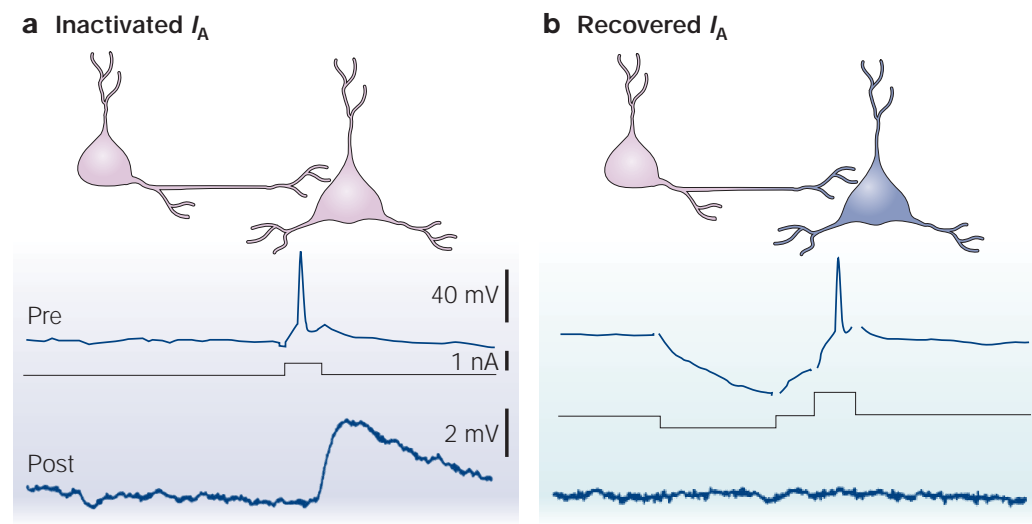

Figure 7 | Gating of action-potential propagation by the potassium current $\mathbf{I}_{A}$.

a | At resting membrane potential, presynaptic $I_{A}$ was inactivated and the action potential evoked in the presynaptic cell propagated and elicited an excitatory postsynaptic potential (EPSP) in the postsynaptic cell. b|Following a brief hyperpolarizing pre-pulse, presynaptic $I_{A}$ recovered from inactivation and blocked propagation. Consequently, no EPSP was evoked by the presynaptic action potential. Adapted, with permission, from REF. 66 ( ) (1997) Macmillan Magazines Ltd. frequencies. But another way that a neuron's branching pattern can affect impulsepropagation is by reflecting the impulse ${ }^{105-107}$. Reflection (or reverse propagation) occurs when an action potential is near failure ${ }^{105}$. This form of axonal computation has been well described in leech mechanosensory neurons ${ }^{75,76}$ (FIG. 8) in which an unexpected event occurs when conduction nearly becomes blocked - theaction potential that has nearly failed to invadethethick branch of the principal axon setsup a local potential that propagates backwards. Reflection occurs because impulses are sufficiently delayed as they travel through the branch point. So, when the delay exceeds the refractory period of the afferent axon, theimpulsewill propagatebackwards as well as forwards, creating a reflection. This phenomenon can be identified electrophysiologically at the cell body of theP neuron because action potentials that reflect have a longer initial rising phase ( or 'foot'), indicating a delay in conduction through the branch point. This fast doublefiring in the thin branch of mechanosensory neurons has important functional consequences. It facilitates synaptic transmission at synapses that are formed by this axon and postsynaptic neurons by a mechanism of paired-pulse facilitation with the orthodromic spike and the antidromic action potential that reflected at the branch point (FIG. 8). Reflection also occurs in $\mathrm{T}$ cells ${ }^{75}$. Interestingly, the facilitation of synaptic transmission also affects the chemical synapse between theP cell and the Sneuron, a neuron that has an essential role in sensitization, a non-associative form of learning ${ }^{76}$. Reflected propagation is not restricted to mechanosensory neurons of theleech but has also been observed in theaxon of an identified snail neuron ${ }^{87}$. Reflection has not yet been definitively reported in mammalian axons (REF. 108) but it has been demonstrated in dendrites (BOX 2).

\section{Axo-axonal coupling and fast synchronization}

Ephapticinteractions. Interactions between neighbouring axons werefirst studied by Katz and Schmitt ${ }^{109,110}$ in the crab. The passage of an impulse through oneaxonal fibre produced a subthreshold changein excitability in the adjacent fibre. As the action potential approached in the active axon, the excitability of the resting fibre was first reduced, then quickly enhanced. This effect results from depolarization of the resting axon by the active axon, which locally generates an extracellular potential of a few mV. Interactions of this typeare called ephaptic (from the Greek for 'touching onto'111) and have also been observed at frog sciatic nerve $e^{112}$.

One of themost interesting features of ephaptic interaction between adjacent axons is that the conduction velocity in neighbouring fibres might beunified, thereby synchronizing activity in a bundle of axons. If oneaction potential precedes the other by a few milliseconds, it accelerates the conduction rate of the lagging action potential in the other axon ${ }^{110}$. However, perfectly synchronized action potentials decrease the conduction velocity in both branches. Synchronization can only occur if the individual velocities differ only slightly and are significant for a sufficient axonal length ${ }^{110}$. Does such synchronization also occur in mammalian axons? 

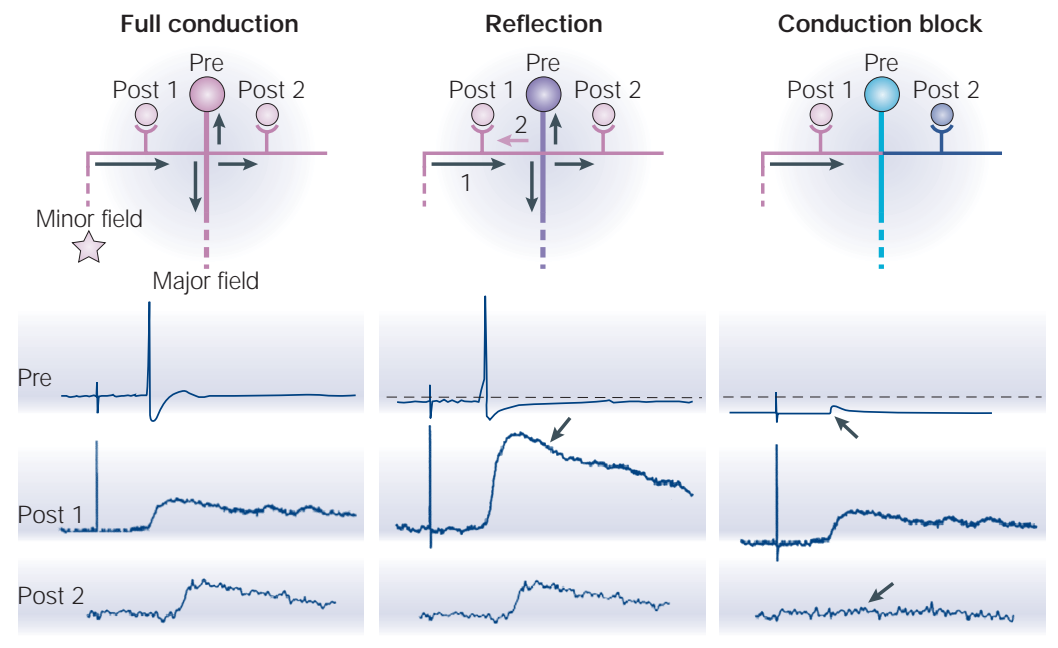

Figure 8 | Reflection of action potentials. Reflection and conduction block produce multilevel synaptic transmission in mechanosensory neurons of the leech. Left, an action potential that is initiated by anterior minor field stimulation invades the whole axonal arborization (pink) and evokes an excitatory postsynaptic potential in all postsynaptic cells. Middle, following repetitive stimulation, the cell body is slightly hyperpolarized (purple) and the same stimulation induces a reflected action potential at the branch point between the left branch and the principal axon. The reflected action potential (pink arrow 2) stimulates the presynaptic terminal on postsynaptic cell 1 twice, thereby enhancing synaptic transmission (arrow in lower panel). Right, when the cell body is further hyperpolarized (turquoise), the stimulation of the minor field now produces an action potential that fails to propagate at the branch point. The failed spike is seen as a spikelet at the cell body (upward arrow). No postsynaptic response is evoked in postsynaptic cell 2 (downward arrow). Adapted, with permission, from REF. 75 (c) (1998) The National Academy of Sciences.

ELECTRICAL SYNAPSE Specialized sites where gapjunction channels bridgethe membrane of adjacent neurons and providea low-resistance pathway for ions and small molecules, thereby permitting direct transmission of electrical signals.
Thereis no evidencefor this yet, but modelling studies indicate that the relative location of nodes of Ranvier on two adjacent myelinated axons might also determine the degree of temporal synchrony between fibres ${ }^{113,114}$. O n small unmyelinated axons, ephaptic interaction betwen axons is predicted to be minimal ${ }^{115}$ but future research might reveal a powerful means to thoroughly synchronizeneuronal activity downstream of the site of action potential initiation.

\section{Box 2 | Reflected propagation in dendrites}

Whether 'ping-pong' propagation occurs in mammalian axons is still debated ${ }^{108}$. However, in mitral cells of the mammalian olfactory bulb, both conduction failures ${ }^{143}$ and reflection ${ }^{121}$ have been observed for impulses that are initiated in dendrites. Propagation in dendrites of mitral cells is unusual. Like propagation in axons, it is highly activeand no decrement in theamplitude of theaction potential is observed between the soma and the dendrite ${ }^{144}$. In addition, mitral cell dendrites are both pre- and postsynaptic elements. Ping-pong propagation
Electrical coupling of axons. Another type of axoaxonal communication has recently been demonstrated in hippocampal neurons. In thehippocampus, one type of high frequency oscillation $(100-200 \mathrm{~Hz})$ called 'ripple' arises from the high-frequency firing of inhibitory interneurons and phase-locked firing of many CA1 neurons ${ }^{116}$. Some of the properties of ripple oscillation are, however, difficult to explain. First, the oscillations are so fast (near $200 \mathrm{~Hz}$ ) that synchrony across many cells would be difficult to achievethrough chemical synaptic transmission. In addition, ripples persist during pharmacological blockade of chemical transmission in vitro ${ }^{117}$. While some inhibitory interneurons might synchronize a large number of pyramidal cells during the ripple ${ }^{118}$, a significant part of the synchronous activity could be mediated by axo-axonal electrical synaptic contacts through gap junctions ${ }^{119}$ (FIG. 9a). Antidromic stimulation of a neighbouring axon elicits a spikelet that has a fast rate of rise (near $180 \mathrm{mV} \mathrm{ms}^{-1}$ ) and an amplitude between 1 and $10 \mathrm{mV}$. Spikel ets can be evoked at the rate of a ripple $(200 \mathrm{~Hz})$ and are blocked by TTX or by the gap junction blocker carbenoxolone. Simultaneous recording from the axon and cell body showed that the spikel et traversed the axon prior to invading the soma and the dendrites. Finally, labelling of pyramidal neurons with rhodamine, a small fluorescent molecule, showed dye coupling in adjacent neurons that was initiated through the axon ${ }^{119}$ (FIG. 9b). M odels indicate that the density of gap junctions might bevery low, accounting for the fact that they have not yet been visualized in axons. But pannexins, a recently identified family of gap-junction proteins that are found throughout the brain, could be the molecular substrate of gapjunctions in axons ${ }^{120}$. So, the function of the axon is not limited to conduction of impulses to theterminal, and information might process between adjacent pyramidal neurons through ELECTRICAL SYNAPSES that are located close to their axon hillock. has been observed following near failure of dendritic action potentials that areevoked in distal primary dendrites ${ }^{121}$. Forward propagation of an action potential (1) in a dendrite (d) can beevoked by an excitatory postysynaptic potential that is licited by strong stimulation of the glomerulus. This particular form of propagation might fail near thecell body when thesoma (s) is slightly hyperpolarized (asterisk, dashed line in theright panel of the figure). For an intermediaterange of membrane potentials, theaction potential invades the soma and might trigger a back-propagating action potential (2), which is observed as a dendritic doublespikein the primary dendrite (thick trace in theright panel of the figure). Thefunction of reflected propagation has not been definitively established, but when axonal output is prevented by inhibition of thesoma, the primary dendrite of the mitral cell can function as a local interneuron affecting its immediate environment. Reflection of fast action potentials has also been observed in dendrites of retinal ganglion cells ${ }^{145}$. Figure adapted, with permission, from REF. 121 () (2002) TheAmerican Physiological Society. 


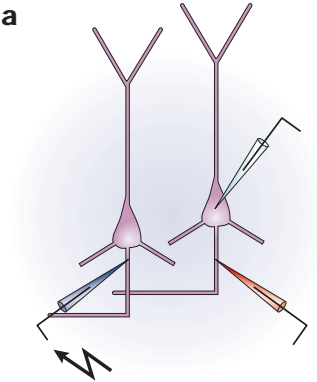

b

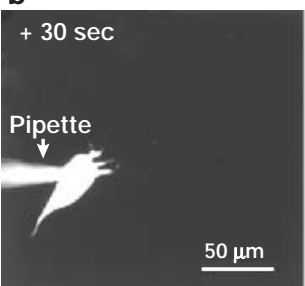

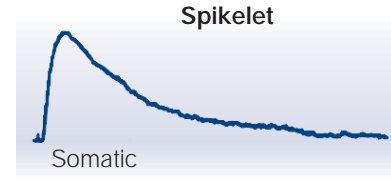
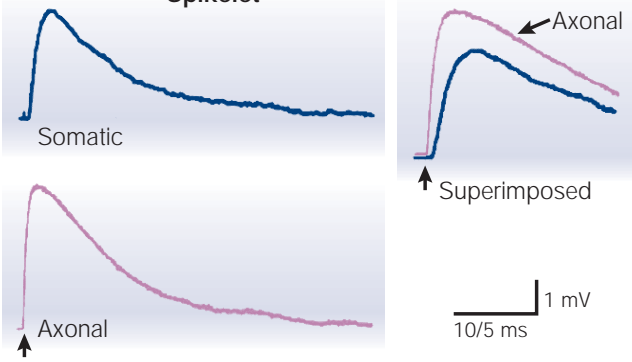

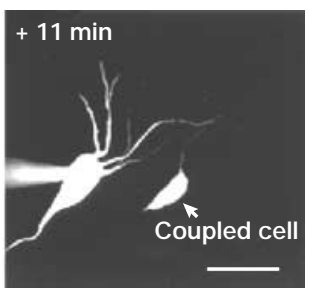

Figure 9 | Axo-axonic coupling of hippocampal pyramidal neurons. a | Spikelets propagate antidromically. Whole-cell recordings were obtained from the soma (blue traces) and from the axon hillock (pink traces). Spikelets were evoked by the stimulation of the axon of a neighbouring neuron. Superimposed traces show a delay between the axonal recording and the somatic recording, indicating that spikelets traverse the axon prior to invading the soma. b | Dye coupling between hippocampal pyramidal neurons. A neuron was recorded in wholecell configuration with a pipette containing a fluorescent dye (+30 sec). Axon and dendrites were labelled about $8 \mathrm{~min}$ after establishing whole-cell configuration. The boxed region shows an axon of a second pyramidal neuron containing dye from the axon of the first cell. The cell body of the dye-coupled pyramidal cell appears a few minutes later (+ $11 \mathrm{~min})$. Adapted, with permission, from REF. 119 @ (2001) Cell Press.

\section{Conclusion \\ Increased computational capabilities. A xons achievesev- eral fundamental operations that go beyond classical propagation. Theoutput messagecan berouted along selected axonal pathways at a defined regime of activity. The consequences of this in mammalian axons arenot yet well understood, but branch point failures might contribute to theelaboration of sensory processing in invertebrateneuron $\mathrm{s}^{74}$. Axonal propagation might also 'bounce back' at a branch point or at the cell body. However, at present, only a handful of examples of reflected propagation have been observed $75,76,87,08,121$. Reflected impulses might limit the spread of theneuronal messageand enhance synaptic transmission. Theoretical and experimental studies indicatethat reflection of action potentials could occur in axons that have large swellings or a branch point with a high GR. Finally, axonal coupling through ephaptic interactions or gap junctions might precisely synchronize network activity ${ }^{119}$. All of these operations increase the computational capabilities of axons and affect the dynamics of synaptic coupling. Many pieces of the puzzleare, however, still missing.}

Futuredirectionsand missing pieces. Axonal morphology has a crucial rolein conduction, and propagation failures or reflected propagation might result from the presence of axonal irregularities such as varicosities and branch points. H owever, detailed quantitative analysis of the morphology of singleaxons is relatively scarce. It will be of great interest to determine the precise number of branch points and GR in several types of mammalian axons to build more realistic models. In particular, the comparison of these parameters in reliableand unreliablecortical axons might reveal unexpected differences. Another fundamental challenge in thenear futurewill be to manipulate local axonal architecture to produce branch points with defined GRs. Local modification of the cytoskeleton in simplemodels of axons could be a powerful tool to addressthisquestion.

Thesubcellular localization of ion channels also has a crucial rolein propagation. In many axons, GR might be greater than 1 and propagation still possibleand reliable. A reasonable explanation for thereliability of conduction is that axonal structures areendowed with a heterogeneous distribution of ion channels. For example, a high density of sodium channels near branch points or at boutons could account for reliableconduction. Detailed quantitative immunostaining of sodium channels on single axonal fibres will beneeded to test this hypothesis. In models of axonal conduction, the density and biophysical properties of ion channels can be easily tested ${ }^{96,122}$. Attaining a detailed understanding of axonal function will also requiremanipulation of theexpression of specific ion channels at precise locations in the axon. The use of recently developed molecular tools to target defined channel subunits to specific axonal compartments could help to determinether rolein axonal propagation ${ }^{123,124}$. For instance, the controlled expression of sodium or potassium channels at a high density at branch points would help us understand branch point failures. Moreover, chromophore assisted laser inactivation of proteins could be used to modify ion channel density along axons in a spatially controlled manner ${ }^{125,126 .}$

Fine temporal tuning can be achieved by axons. Differences in axonal length in theterminal axonal tuft introduce delays of several milliseconds. Is temporal scaling of action potential propagation in theaxonal arborization relevant to the coding of neuronal information? Differential conduction delays in axonal branches contributeto precise temporal coding in the barn owl auditory system ${ }^{59-61}$. But a role for axonal delays in synchronizing mammalian networks ${ }^{127}$ is yet to be demonstrated. Local axonal interactions such as ephaptic coupling and gap-junction coupling allow fast synchronization of activity in neighbouring neurons. Surprisingly, littleexperimental effort has been devoted to ephaptic interactions, which area powerful means of precisely synchronizing theoutputs of neighbouring neurons. Perhaps ephaptic interactions between parallel axons could compensatefor the 'stuttering conduction' that resultsfrom axonal varicosities and branch points ${ }^{67}$. The role of these mechanisms in synchronizing activity will haveto bedetermined in axonsthat havea geometrical arrangement that is favourable for ephaptic coupling (that is, fasciculation over a sufficient axonal length). Callosal axons, mossy fibres and Schaffer collaterals are possibleexperimental subjects. In the case of gapjunction coupling, it will be important to determine whether electrical coupling also favours synchronization of neocortical neurons. The molecular substrates of electrical coupling in axons will need to beidentified - pannexinshavealready been proposed ${ }^{120}$. 
New methods of investigation. M ost of our knowledge about axonal computation is derived from experiments on invertebrate neurons or from computer simulations $\mathrm{s}^{128}$. O ur understanding of propagation in mammalian axons isstill fragmentary and direct evidencefor propagation failures is still controversial $99,101,129,130$. Moreover, evidencefor an important role of propagation failuresand axonal reflection in information processing in vivo is still scarce ${ }^{77,108}$. A main difficulty in studying propagation along thin unmyelinated axonsistheir relativecomplexity and their small size, which makedirect electrophysiological recordings almost impossible. New tools and experimental techniques will need to be developed if the mechanisms of axonal computation in mammalian CNS neurons areto bedissected. High resolution imaging techniques like multiphoton confocal microscopy ${ }^{42,101,102}$ or voltage-sensitive dye ${ }^{67,87}$ haveenormous potential. But it will al so beextremely important to use other probes that do not perturb the rather fragile equilibrium that underlies propagation. Non-invasive recording techniquessuch as extracellular recording from singleaxons will beextremely helpful|39,81,100,131.

Dendrites have recently received a great deal of attention and substantial progress has been made in understanding their function ${ }^{132-134}$. Axons deservecomparable attention so that their complex properties can be fully explored. We predict that future investigation will reveal that fundamental neuronal operations are not only achieved by thecell body, the dendrites and the synapse. Axonal operations will also be shown to be important determinants of information processing in the brain.
1. Ramón y Cajal, S. Histologie du Système Nerveux (Maloine, Paris, 1911)

2. Huxley, A. From overshoot to voltage clamp. Trends Neurosci. 25, 553-558 (2002)

3. Poliak, S. \& Peles, E. The local differentiation of myelinated axons at nodes of ranvier. Nature Rev. Neurosci. 4, 968-980 (2003).

4. Bostock, H., Sherrat, R. M. \& Sears, T. A. Overcoming conduction failure in demyelinated nerve fibres by proloning action potentials. Nature 274, 385-387 (1978).

5. Bostock, H., Sears, T. A. \& Sherratt, R. M. The effects of 4 aminopyridine and tetraethylammonium ions on normal and demyelinated mammalian nerve fibres. J . Physiol. (Lond.) 313, 301-315 (1981).

6. Sheng, M. Tsaur, M. L., J an, Y. N. \& J an, L. Y. Subcellular segregation of two A-type $\mathrm{K}^{+}$channel protein in rat central neurons. Neuron 9, 243-259 (1992).

7. Sheng, M., Liao, Y. J ., J an, Y. N. \& J an, L. Y. Presynaptic Acurrent based on heteromultimeric $\mathrm{K}^{+}$channels detercted in vivo. Nature 365, 72-75 (1993)

8. Wang, H., Kunkel, D. D., Martin, T. M., Schwarztkroin, P. A. $\&$ Tempel, B. L. Heteromultimeric $\mathrm{K}^{+}$channels in terminals and juxtaparanodal regions of neurons. Nature $365,75-79$ (1993).

9. Wang, H., Kundel, D. D., Schwartzkroin, P. A. \& Tempel, B. L. Localization of $K, 1.1$ and $K, 1.2$, two $K$ channel proteins, to synaptic terminals, somata, and dendrites in the mouse brain. I. Neurosci. 14, 4588-4599 (1994).

10. Veh, R. W. et al. Immunohistochemical localization of five members of the $K_{v} 1$ channel subunits: contrasting subcellular locations and neuron-specific co-localizations in rat brain. Eur. J . Neurosci. 7, 2189-2205 (1995)

11. Cooper, E. C., Milroy, A., J an, Y. N., J an, L. Y. \& Lowenstein, D. H. Presynaptic localization of $\mathrm{K}_{v}$ 1.4-containing A-type potassium channels near excitatory synapses in the hippocampus. J. Neurosci. 18, 965-974 (1998).

12. Devaux, J. et al. $K_{v} 3.1 b$ is an novel component of CNS nodes. J. Neurosci. 23, 4509-4518 (2003).

13. Dodson, P. D. et al. Presynaptic rat $K_{v} 1.2$ channels suppress synaptic terminal hyperexcitability following action potential invasion. J. Physiol. (Lond.) 550, 27-33 (2003).

14. Ishikawa, $\mathrm{T}$. et al. Distinct roles of $\mathrm{K}, 1$ and $\mathrm{K}, 3$ potassium channels at the Calyx of Held presynaptic terminal. I. Neurosci. 23, 10445-10453 (2003)

15. J onas, P., Koh, D. S., Kampe, K., Hermsteiner, M. \& Vogel, W. ATP-sensitive and $\mathrm{Ca}$-activated $\mathrm{K}$ channels in vertebrate as novel links between metabolism and excitability. Pflugers Arch. 418, 68-73 (1991).

16. Kraus, H. G. et al. Distribution of high-conductance $\mathrm{Ca}^{2+}$ activated $\mathrm{K}^{+}$channels in rat brain: targeting to axons and nerve terminals. I. Neurosci. 16, 955-963 (1996).

17. Bielefeldt, K. \&l ackson, M. B. A calcium-activated potassium channel causes frequency-dependent actionpotential failures in a mammalian nerve terminal. J. Neurophysiol. 70, 284-298 (1993)

18. $\mathrm{Hu}, \mathrm{H}$. et al. Presynaptic $\mathrm{Ca}^{2+}$-activated $\mathrm{K}^{+}$channels in glutamatergic hippocampal terminals and their role in spike repolarization and regulation of transmitter release. J. Neurosci. 21, 9585-9597 (2001)

19. Roncarati, R., Di Chio, M., Sava, A., Terstappen, G. C. \& Fumagalli, G. Presynaptic localization of the small conductance calcium-activated potassium channel SK3 at the neuromuscular junction. Neuroscience 104, 253-262 (2001).
20. Koh, D. S., J onas, P. \& Vogel, W. Na+-activated K+ channels localized in the nodal region of myelinated axons of Xenopus. J. Physiol. (Lond.) 479, 183-197 (1994)

21. Bhattacharjee, A., Gan, L. \& Kaczmarek, L. K. Localization of the Slack potassium channel in the rat central nervous system. J. Comp. Neurol. 454, 241-254 (2002).

22. Baker, M., Bostock, P., Grafe, P. \& Martins, P. Function and distribution of three types of rectifying channel in rat spinal root myelinated axons. J . Physiol. (Lond.) 383, 45-87 (1987).

23. Angstadt, J . D. \& Calabrese, R. L. A hyperpolarizationactivated inward current in heart interneurons of the medicinal leech. J. Neurosci. 9, 2846-2857 (1989).

24. Eng, D. L., Gordon, T. R., Kocsis, J. D. \& Waxman, S. G. Current-clamp analysis of a time-dependent rectification in rat optic nerve. J. Physiol. (Lond.) 421, 185-202 (1990).

25. Beaumont, V. \& Zucker, R. S. Enhancement of synaptic transmission by cyclic AMP modulation of presynaptic I channels. Nature Neurosci. 3, 133-141 (2000).

26. Beaumont, V., Zhong, N., Froemke, R. C., Ball, R. W. \& Zucker, R. S. Temporal synaptic tagging by $\mathrm{I}_{\mathrm{h}}$ activation and actin: involvement in long-term facilitation and CAMP-induced synaptic enhancement. Neuron, 33, 601-613 (2002).

27. Southan, A. P., Morris, N. P., Stephens, G. J \& \& Robertson, B Hyperpolarization-activated currents in presynaptic terminals of mouse cerebellar bascket cells. J. Physiol. (Lond.) 526, 91-97 (2000)

28. Cuttle, M. F., Rusznak, Z., Wong, A. Y., Owens, S. \& Forsythe, I. Modulation of a presynaptic hyperpolarizationactivated cationic current $\left(I_{h}\right)$ at an excitatory synaptic terminal in the rat auditory brainstem. J. Physiol. (Lond.) 534, 733-744 (2001).

29. Strübing, C., Krapivinsky, G., Krapivinsky, L. \& Clapham, D. E. TRPC 1 and TRPC 5 form a novel cation channel in mammalian brain. Neuron 29,645-655 (2001).

30. Greka, A., Navarro, B., Oancea, E., Duggan, A. \& Clapham D. E. TRPC 5 is a regulator of hippocampal neurite length and growth cone morphology. Nature Neurosci. 6, 837-845 (2003).

31. Geiger, J . R. P. \& J onas, P. Dynamic control of presynaptic $\mathrm{Ca}^{2+}$ inflow by fast-inactivating $\mathrm{K}^{+}$channels in hippocampal mossy fiber boutons. Neuron 28, 927-939 (2000). With elegant recording techniques this paper shows that repetitive axon stimulation inactivates A-type potassium channels, broadens presynaptic action potassium channels, broadens presynaptic action
potentials and facilitates synaptic transmission.
Rhodes, K. J . et al. Association and colocalization of the

32. Rhodes, $\mathrm{K}$. J . et al. Association and colocalization of the
$\mathrm{K} \beta 1$ and $\mathrm{K}_{\gamma} \beta 2 \beta$-subunits with $\mathrm{K}_{\psi} 1 \alpha$-subunits in mammalia brain $\mathrm{K}^{+}$channel complexes. J. Neurosci. 17, 8246-8258 (1997).

33. Grossman, Y., Parnas, I. \& Spira, M. E. Differential conduction block in branches of a bifurcating axon. J. Physiol. (Lond.) 295, 283-305 (1979). Demonstration and analysis of differential propagation block at the branch point of a lobster peripheral axon.

34. Wang, L. Y. \& Kaczmarek, L. K. High-frequency firing help replenish the readily releasable pool of synaptic vesicles. Nature 394, 384-388 (1998)

35. Madeja, M. Do neurons have a reserve of sodium channels for the generation of action potentials? A study on acutely isolated CAl neurons from the guinea-pig hippocampus. Eur. J. Neurosci. 12, 1-7 (2000).
36. Brody, D. L. \&Yue, D. T. Release-independent short-term synaptic depression in cultured hippocampal neurons. J. Neurosci. 20, 2480-2494 (2000). Evidence that sodium channel inactivation might participate in short-term synaptic depression at autaptic contacts.

37. Prakriya, M. \& Mennerick, S. Selective depression of lowrelease probability excitatory synapses by sodium channel blockers. Neuron 26, 671-682 (2000)

Differential sensitivity of glutamatergic and GABAmediated axons to low concentrations of sodium channel blockers.

38. He, Y., Zorumski, C. F. \& Mennerick, S. Contribution of presynaptic $\mathrm{Na}^{+}$channel inactivation to paired-pulse synaptic depression in cultured hippocampal neurons. J. Neurophysiol. 87, 925-936 (2002).

39. Meeks, J. P. \& Mennerick, S. The selective effects of potassium elevation on glutamate signaling and action potential conduction in hippocampus. J . Neurosci. 24 197-206 (2004).

40. Martina, $\mathrm{M}$. \& J onas, P. Functional differences in $\mathrm{Na}^{+}$channel gating between fast-spiking interneurones and principal neurons of rat hippocampus. J. Physiol. (Lond) 505, 593-603 (1997).

41. Martina, M., Vida, I. \& J onas, P. Distal initiation and active propagation of action potentials in interneurons dendrites. Science 287, 295-300 (2000).

42. Forti, L., Pouzat, C. \& Llano, I. Action potential-evoked $\mathrm{Ca}^{2+}$ signals and calcium channels in axons of developing rat cerebellar interneurones. J. Physiol. (Lond). 527, 33-48 (2000).

43. Tan, Y. P. \& Llano, I. Modulation by $\mathrm{K}^{+}$channels of action potential-evoked intracellular $\mathrm{Ca}^{2+}$ concentration rises in rat cerebellar basket cell axons. J . Physiol. (Lond.) 520, 65-78 (2000).

44. Antonini, A., Gillespie, D. C., Crair, M. C. \& Stryker, M. P. Morphology of single geniculocortical afferents and functional recovery of the visual cortex after reverse monocular deprivation in the kitten. J . Neurosci. 18, 9896-9909 (1998).

45. Petersen, C., Grinvald, A. \& Sakmann, B. S patiotemporal dynamics of sensory responses in layer $2 / 3$ of rat barrel cortex measured in vivo by voltage-sensitive dye imaging combined with whole-cell voltage recordings and neuron reconstructions. J. Neurosci. 23, 1298-1309 (2003)

46. Ishizuka, N., Weber, J. \& Amaral, D. G. Organization of intrahippocampal projections originating from CA3 pyramidal cells in the rat. J . Comp. Neurol., 295, 580-623 (1990).

47. Major, G., Larkman, A. U., J onas, P., Sakmann, B. \& J ack, J . J . B. Detailed passive cable models of whole-cell recorded CA3 pyramidal neurons in rat hippocampal slices. J. Neurosci. 14, 4613-4638 (1994).

48. Li, X., Somogyi, P., Ylinen, A. \& Buzsaki, G. The hippocampal CA3 network: an in vivo intracellular labeling study. J . Comp. Neurol. 339, 181-208 (1994).

49. Gulyas, A. I., Miles, R., Hajos, N. \& Freund, T. Precision and variability in postsynaptic target selection of inhibitory cells in the hippocampus CA3 region. Eur. J . Neurosci. 5, 1729-1751 (1993).

50. Guillery, R. W. Branching thalamic afferents link action and perception. J. Neurophysiol. 90, 539-548 (2003).

51. Pinault, D. \& Deschênes, M. Projection and innervation patterns of individual thalamic reticular axons in the thalamus of the adult rat: a three-dimensional, graphic, and morphometric analysis. J. Comp. Neurol. 391, 180-203 (1998). 
52. Westrum, L. E. \& Blackstad, T. W. An electron microscopic study of the stratum radiatum of the rat hippocampus (regio superior, CA1) with particular emphasis on synaptology. J. Comp. Neurol. 119, 281-309 (1962)

53. Shepherd, G. M. G. Raastad, M. \& Andersen, P. General and variable features of varicosity spacing along unmyelinated axons in the hippocampus and cerebellum. Proc. Natl Acad. Sci. USA 99, 6340-6345 (2002).

54. Blackstad, T. W. \& Kjaerheim, Å. Special axo-dendritic synapses in the hippocampal cortex: electron and light microscopic studies in the hippocampal cortex: electron and light microscopic studies on the layer of mossy fibers. J. Comp. Neurol. 117, 133-146 (1961)

55. Shepherd, G. M. G. \& Raastad, M. Axonal varicosity ditributins along parallel fibers: a new angle on a cerebella circuit. Cerebellum 2, 110-113 (2003).

56. Young, J . Z. The giant nerve fibres and epistellar body of cephalopods. Q. J . Microsc. Sci. 78, 367-386 (1936).

57. Berbel, P. \& Innocenti, G. M. The development of the corpus callosum: a light and electromicroscopic study. J. Comp. Neurol. 276, 132-156 (1988)

58. Chung, S. H., Raymond, S. A. \& Lettvin, J. Y. Multiple meaning in single visual units. Brain Behav. Evol. 3, 72-101 (1970)

59. Carr, C. E. \& Konishi, M. Axonal delay lines for time measurement in the owl's brainstem. Proc. Natl Acad. Sci. USA 85, 8311-8315 (1988).

60. Carr, C. E. \& Konishi, M. A circuit for detection of interaura time differences in the brain stem of the barn owl. J. Neurosci. 10, 3227-3246 (1990)

61. McAlpine, D. \& Grothe, B. Sound localization and delay lines - do mammals fit the model? Trends Neurosci. 26, 347-350 (2003).

62. Manor, Y., Koch, C. \& Segev, I. Effect of geometrical irregularities on propagation delay in axonal trees. Biophys. J 60, 1424-1437 (1991).

\section{A theoretical study showing how the numerous} branch points introduce a delay of conduction in axon collaterals.

63. Lüscher, C., Streit, J . Quadroni, R. \& Lüscher, H. R. Action potential propagation through embryonic dorsal root ganglion cells in culture. I. Influence of the cell morphology on propagation properties. J . Neurophysiol. 72, 622-633 (1994).

64. Hatt, H. \& Smith, D. O. Synaptic depression related to presynaptic axon conduction block. J. Physiol. (Lond.) 259, 367-393 (1976).

65. Streit, J., Lüscher, C. \& Lüscher, H. R. Depression of postsynaptic potentials by high frequency stimulation in embryonic motoneurons grown in spinal cord slice cultures. J. Neurophysiol. 68, 1793-1803 (1992).

66. Debanne, D., Guérineau, N. C., Gähwiler, B. H. \& Thompson, S. M. Action potential propagation gated by an I-like $\mathrm{K}^{+}$conductance in hippocampus. Nature $\mathbf{3 8 9}$ 286-289 (1997).

Failures of transmission interpreted as propagation failures are observed in hippocampal neurons when the presynaptic action potential is evoked following a transient somatic hyperpolarization.

67. Muschol, M., Kosterin, P., Ichikawa, M. \& Salzberg, B. M. Activity-dependent depression of excitability and calcium transients in the neurohypophysis suggests a model of 'stuttering conduction'. I. Neurosci. 23, 11352-11362 (2003)

68. Barron, D. H. \& Matthews, B. H. C. Intermittent conduction in the spinal cord. J. Physiol. (Lond.) 85, 73-103 (1939.

69. Krnjevic, K. \& Miledi, R. Presynaptic failure of neuromuscular propagation in rats. J. Physiol. (Lond.) 149, 1-22 (1959).

70. Parnas, I. Differential block at high frequency of branches of a single axon innervating two muscles. J. Neurophysiol. 35, 903-914 (1972).

71. Smith, D. O. Mechanisms of action potential propagation failure at sites of axon branching in the crayfish. J. Physiol. (Lond.) 301, 243-259 (1980).

72. Van Essen, D. C. The contribution of membran hyperpolarization to adaptation and conduction block in sensory neurones of the leech. J. Physiol. (Lond.) 230, 509-534 (1973).

73. Yau, K. W. Receptive fields, geometry and conduction block of sensory neurons in the CNS of the leech. J. Physiol. (Lond.) 263, 513-538 (1976)

74. Gu, X. Effect of conduction block at axon bifurcations on synaptic transmission to different postsynaptic neurons in the leech. J. Physiol. (Lond.) 441, 755-778 (1991).

75. Baccus, S. A. Synaptic facilitation by reflected action potentials: enhancement of transmission when nerve impulses reverse direction at axon branch points. Proc. Natl Acad. Sci. USA 95, 8345-8350 (1998)

Experimental evidence that action potential propagation might reflect at branch points of invertebrate axons. Reflected action potentials facilitates synaptic transmission.
76. Baccus, S. A., Burrell, B. D., Sahley, C. L. \& Muller, K. J . Action potential reflection and failure at axon branch points cause stepwise changes in EPSPs in a neuron essential for learning. . . Neurophysiol. 83, 1683-1700 (2000)

77. Deschênes, M. \& Landry, P. Axonal branch diameter and spacing of nodes in the terminal arborization of identified thalamic and cortical neurons. Brain Res. 191, 538-544 (1980).

78. Ducreux, C., Reynaud, J . C. \& Puizillout, J . J . Spike conduction properties of T-shaped $C$ neurons in the rabbit nodose ganglion. Eur. J. Physiol. 424, 238-244 (1993).

79. Lüscher, C., Streit, ]., Lipp, P. \& Lüscher, H. R. Action potential propagation through embryonic dorsal root ganglion cells in culture. II. Decrease of conduction reliability during repetitive stimulation. J . Neurophysiol. 72, 634-644 (1994)

80. Dyball, R. E., Grossmann, R., Leng, G. \& Shibuki, K. Spike propagation and conduction failure in rat neural lobe. J. Physiol. (Lond) 401, 241-256 (1988).

81. Soleng, A. F., Chiu, K. \& Raastad, M. Unmyelinated axons in the rat hippocampus hyperpolarize and activate an $\mathrm{H}$ current when spike frequency exceeds $1 \mathrm{~Hz}$. J . Physiol. (Lond.) 552, 459-470 (2003). This paper suggests that $\mathrm{I}_{\mathrm{h}}$ might act as an homeostatic current for the conduction of repetitive action potentials.

82. Grossman, Y., Parnas, I. \& Spira, M. E. lonic mechanisms involved in differential conduction of action potentials at high frequency in a branching axon. J. Physiol. (Lond.) 295 307-322 (1979).

83. Smith, D. O. Morphological aspects of the safety factor for action potential propagation at axon branch points. J. Physiol. (Lond.) 301, 261-269 (1980).

84. Bourque, C. W. Intraterminal recordings from the rat neurohypophysis in vitro. J. Physiol. (Lond.) 421, 247-262 (1990).

85. Zhang, S. J \& \& ackson, M. B. GABA-activated chloride channels in secretory nerve endings. Science $\mathbf{2 5 9}, 531-534$ (1993).

86. J ackson, M. B. \& Zhang, S. J . Action potential propagation block by $G A B A$ in rat posterior pituitary nerve terminals. J. Physiol. (Lond.) 483, 597-611 (1995)

87. Antic, S., Wuskell, J . P., Loew, L. \& Zecevic, D. Functional profile of the giant metacerebral neuron of Helix aspersa: temporal and spatical dynamics of electrical activity in situ. J. Physiol. (Lond.) 527, 55-69 (2000).

\section{. Physiol (Lond.) $527,55-69$ (2000). A multi-optical recording study with voltage-sensitive} dyes of propagation failures in central neurons of the snail.

88. Macagno, E. R., Muller, K. J \& \& Pitman, R. M. Conduction block silences parts of a chemical synapse in the leech central nervous system. J . Physiol. (Lond) 387, 649-664 (1987).

89. Muller, K. J \& \& Scott, S. A. Transmission at a 'direct' electrical connexion mediated by an interneurone in the leech. J. Physiol. (Lond.) 311, 565-583 (1981).

90. Eng, D. L. \& Kocsis, J. D. Activity-dependent changes in extracellular potassium and excitability in turtle olfactory nerve. J. Neurophysiol. 57, 185-202 (1987)

91. Poolos, N. P., Mauk, M. D. \& Kocsis, J. D. Activity-evoked increases in intracellular potassium modulate presynaptic excitability in the CAl region of the hippocampus. J. Neurophysiol. 58, 404-416 (1987).

92. Heitler, W. J \& \&oodman, C. S. Multiple sites of spike initiation in a bifurcating locust neurone. J. Exp. Biol. 76, 63-84 (1978).

93. Ritchie, J . M. \& Straub, R. W. The after-effects of repetitive stimulation on mammalian non-medulated fibres. J . Physio (Lond.) 134, 698-711 (1956).

94. Ritchie, J. M. \& Straub, R. W. The hyperpolarization which follows activity in mammalian non-medulated fibres. J. Physiol. (Lond.) 136, 80-97 (1957)

95. Mar, A. \& Drapeau, P. Modulation of conduction block in leech mechanosensory neurons. J. Neurosci. 16 4335-4334 (1996)

96. Kopysova, I. L. \& Debanne, D. Critical role of axonal A-type $\mathrm{K}^{+}$-channels and axonal geometry in the gating of action potential propagation along CA3 pyramidal cell axons: simulation study. J. Neurosci. 18, 7436-7451 (1998).

97. Obaid, A. L. \& Salzberg, B. M. Micromolar 4-aminopyridine enhances invasion of a vertebrate neurosecretary terminal arborization. J . Gen. Physiol. 107, 353-368 (1996)

98. Mackenzie, P. J ., Umemiya, M. \& Murphy, T. H. Ca2+imaging of CNS axons in culture indicate reliable coupling between single action potentials and distal functional release sites. Neuron 16, 783-795 (1996).

99. Mackenzie, P. J \& M Murphy, T. H. High safety factor for action potential conduction along axons but not dendrites of cultured hippocampal and cortical neurons. J . Neurophysiol. 80, 2089-2101 (1998).

100. Raastad, M. \& Shepherd, G. Single-axon action potentials in the rat hippocampal cortex. J . Physiol. (Lond.) 548, 745-752 (2003)
101. Cox, C. L., Denk, W., Tank, D. W. \& Svoboda, K. Action potentials reliably invade axonal arbors of rat neocortical neurons. Proc. Natl Acad. Sci. USA 97, 9724-9728 (2000).

102. Koester, H. J \& Sakmann, B. Calcium dynamic associated with action potentials in single nerve terminals of pyramidal cells in layer $2 / 3$ of the young rat neocortex. J. Physiol. (Lond.) 529, 625-646 (2000).

103. Debanne, D., Kopysova, I. L., Bras, H. \& Ferrand, N. Gating of action potential propagation by an axonal A-like potassium conductance in the hippocampus: a new type of nonsynaptic plasticity. J. Physiol. (Paris) 93, 285-296 (1999).

104. Saviane C., Mohajerani, M. H. \& Cherubini, E. An I like current that is downregulated by $\mathrm{Ca}^{2+}$ modulates information coding at CA3-CA3 synapses in the rat hippocampus. J. Physiol. (Lond.) 552, 513-524 (2003).

105. Goldstein, S. \& Rall, W. Changes of action potential shape and velocity for changing core conductor geometry. Biophys. J. 14, 731-757 (1974).

This theoretical paper sets the rules for the role of local axon geometry on the properties of axon conduction.

106. Ramon, F., J oyner, R. W. \& Moore, J . W. Propagation of action potentials in inhomogeneous axon regions. Fed Proc. 34, 1357-1363 (1975)

107. Parnas, I. in The Neurosciences (eds Schmitt, F. O. \& Worden F. G.) 499-512 (MIT Press, Cambridge, Massachusetts, 1979).

108. Isope, P., Franconville, R., Barbour, B. \& Ascher, P. Repetitive firing of rat cerebellar parallel fibres after a single stimulation. J . Physiol. (Lond.) 554, 829-839 (2004).

109. Katz, B. \& Schmitt, O. Electric interaction between two adjacent nerve fibres. J. Physiol. (Lond.) 97, 471-488 (1940).

110. Katz, B. \& Schmitt, O. A note on interaction between nerve fibers. J. Physiol. (Lond.) 100, 369-371 (1942).

111. Arvanitaki, A. Effects evoked in an axon by the activity of a contiguous one. J. Neurophysiology 5, 89-108 (1942).

112. Kocsis, J. D. Ruiz, J. A. \& Cummins, K. L. Modulation of axonal excitability mediated by surround electrical activity: an intra-axonal study. Exp. Brain Res. 47, 151-153 (1982).

113. Binczak, S., Eilbeck, J. C. \& Scott, A. C. Ephaptic coupling between myelinated nerve fibers. Physicia D 148, 159-174 (2001).

114. Reutskiy, S., Rossoni, E. \& Tirozzi, B. Conduction in bundles of demyelinated nerve fibers: computer simulation. Biol. Cybern. 89, 439-448 (2003).

115. Holt, G. A. \& Koch, C. Electrical interactions via the extracellular potential near cell bodies. J . Comput. Neurosci. 6, 169-184 (1999).

116. Traub, R. D. et al. Axonal gap junctions between neurons: a novel source of network oscillations and perhaps epileptogenesis. Rev. Neurosci. 13, 1-30 (2002).

117. Draguhn, A., Traub, R. D., Schmitz, D. \& J efferys, J . G. R. Electrical coupling underlies high-frequency oscillations in the hippocampus in vitro. Nature 394, 189-192 (1998).

118. Klausberger, T. et al. Brain-state- and cell-type-specific firing of hippocampal interneurons in vivo. Nature $\mathbf{4 2 1}, 844-848$ (2003)

119. Schmitz, D. et al. Axo-axonal coupling: a novel mechanism for ultrafast neuronal communication. Neuron 31, 831-840 (2001).

Axons of CA1 pyramidal cells are electrically coupled through gap junctions.

120. Bruzzone, R., Hormudzi, S. G., Barbe, M. T., Herb, A. \& Monyer, $H$. Pannexins, a family of gap junction proteins expressed in brain. Proc. Natl Acad. Sci. USA $\mathbf{1 0 0}$ 13644-13649 (2003).

121. Chen, W. R., Shen, G. Y., Shepherd, G. M., Hines, M. L. \& Midtgaard, J . Multiple modes of action potential initiation and propagation in mitral cell primary dendrite. J. Neurophysiol. 88, 2755-2764 (2002) First experimental evidence for reflection of action potential propagation in an axon-like dendrite of potential propagation in

122. Segev, l. Computer study of presynaptic inhibition controlling the spread of action potentials into axon terminals. J . Neurophysiol. 63, 987-998 (1990).

123. Garrido, J . et al. A targeting motif that determines sodium channel clustering at the axonal initial segment. Science 300, 2091-2094 (2003).

124. Gu, C., J an, Y. N. \& J an, L. Y. A conserved domain in axonal targeting of $\mathrm{K}_{\mathrm{v}} \mathrm{I}$ (Shaker) voltage-gated potassium channels. Science 301, 646-649 (2003).

125. J ay, D. G. Selective destruction of protein function by chromophore-assisted laser inactivation. Proc. Natl Acad. Sci. USA 85, 5454-5458 (1988).

126. Wong, E., David, S., J acob, M. H. \& J ay, D. G. Inactivation of myelin-associated glycoprotein enhances optic nerve regeneration. J . Neurosci. 23, 3112-3117 (2003)

127. Maex, R. \& De Schutter, E. Resonant synchronization in heterogeneous networks of inhibitory neurons. J. Neurosci. 23, 10503-10514 (2003) 
128. Segev, I. \& Schneidman, E. Axons as computing devices: basic insights gained from models. J. Physiol. (Paris) 93 263-270 (1999).

129. Vincent, P. \& Marty, A. (1996) Fluctuations of inhibitory postsynaptic currents in Purkinje cells from rat cerebella slices. J. Physiol. (Lond.) 494, 183-199 (1996).

130. Huguenard, J. R. Reliability of axonal propagation: the spike doesn't stop here. Proc. Natl Acad. Sci. USA. 97, 9349-9350 (2000).

131. Debanne, D. \& Russier, M. Axonal propagation: does the spike stop here? J. Physiol. (Lond.) 548, 663

132. Häusser, M., Spruston, N. \& Stuart, G. J . Diversity and dynamics of dendritic signaling. Science 290, 739-744 (2000).

133. Segev, I. \& London, M. Untangling dendrites with quantitative models. Science 290, 744-750 (2000)

134. Williams, S. R. \& Stuart, G. J . Role of dendritic synapse location in the control of action potential output. Trends Neurosci. 26, 147-154 (2003).

135. Parnas, I., Hochstein, S. \& Parnas, H. Theoretical analysis of parameters leading to frequency modulation along an inhomogeneous axon. J. Neurophysiol. 39, 909-923 (1976)

136. Lüscher, H. R. \& Shiner, J . S. Computation of action potential propagation and presynaptic bouton activation in terminal arborizations of different geometries. Biophys. J . 58 1377-1388 (1990)

137. Lüscher, H. R. \& Shiner, J . S. Simulation of action potentia propagation in complex terminal arborizations. Biophys. J . 58, $1389-1399(1990)$

138. Graham, B. \& Redman, S. A simulation of action potentials in synaptic boutons during presynaptic inhibition. J. Neurophysiol. 71, 538-549 (1994).

139. Goldfinger, M. D. Computation of high safety factor impulse propagation at axonal branch points. NeuroReport 11, 449-456 (2000).

140. Zhou, L. \&Chiu, S. Y. Computer model for action potential propagation through branch point in myelinated nerves. . Neurophysiol. 85, 197-210 (2001).

141. Rall, W. Branching dendritic trees and motoneuron membrane resistivity. Expl. Neurol. 1, 491-527 (1959).

142. Rall, W. in Neural Theory of Modeling (ed. Reiss, F. P.) 73-97 (Standford Univ. Press, Palo Alto, 1964).

143. Chen, W. R., Midtgaard, J . \& Shepherd, G. M. Forward and backward propagation of dendritic impulses and their synaptic control in mitral cells. Science 278, 463-467 (1997)

144. Bischofberger, J . \&J onas, P. Action potential propagation into the presynaptic dendrites of rat mitral cells. J . Physiol. (Lond.) 504, 350-365 (1997).
145. Velte, T. J \& Masland, R. H. Action potentials in the dendrites of retinal ganglion cells. J. Neurophysiol. 81, 1412-1417 (1999).

Acknowledgements

This study was supported by Centre National de la Recherche Scientifique, Ministry of Research ('Actions Incitatives ] eunes Chercheurs' 5169) Institut National de la Santé et de la Recherche Médicale (Programme 'Avenir'), and Fondation pour la Recherche Médicale. I thank G. Rougon for her support, S. Binzcak, T. Freund, P. Somogyi, E. Carlier, S. Boudkkazi \& N. Ankri for helpful discussions, and M. Seagar for his constant support and constructive criticisms on the manuscript.

Competing interests statement

The author declares that he has no competing financial interests.

\section{DATABASE}

The following terms in this article are linked online to:

LocusLink: http://www.ncbi.nlm.nih.gov/LocusLink

$\mathrm{K}_{\mathrm{v}} 1.1\left|\mathrm{~K}_{\mathrm{v}} 1.2\right| \mathrm{K}_{\mathrm{v}} 1.4\left|\mathrm{~K}_{\mathrm{v}} 3.1\right| \mathrm{K}_{\mathrm{v}} 3.4 \mid$ TRPC1 |TRPC5

Access to this interactive links box is free online. 